\title{
Resolving the mycorrhizal status of important northern hemisphere trees
}

\author{
Mark C. Brundrett $(\mathbb{D} \cdot$ Leho Tedersoo
}

Received: 13 December 2019 / Accepted: 28 June 2020

(C) Springer Nature Switzerland AG 2020

\begin{abstract}
Aims Knowledge about mycorrhizal associations is important for understanding mineral nutrition, stress tolerance and regeneration dynamics of trees. Here we address the mycorrhizal status of 940 species of important trees growing in ecosystems or cultivated in temperate regions of the Northern Hemisphere by resolving conflicting mycorrhizal trait information.

Results Using 3800 observations from the FungalRoot database, we show that mycorrhizal status is highly consistent within species, genera and most families. Most contradictory mycorrhizal designations result from putative diagnosis errors, such as reported ectomycorrhizas EcM) in otherwise arbuscular mycorrhizal (AM) trees (10\% of records). Furthermore, the most commonly studied species are more likely to have incorrect designations in databases due to accumulation of errors. Here we provide a definitive mycorrhizal status based on careful
\end{abstract}

Responsible Editor: Alexia Stokes.

M. C. Brundrett $(\bowtie)$

School of Biological Sciences, University of Western Australia, 35

Stirling Highway, Crawley, WA 6009, Australia

e-mail: mark.brundrett@uwa.edu.au

L. Tedersoo

Department of Mycology and Microbiology, University of Tartu, 14a Ravila, 50411 Tartu, Estonia

e-mail: leho.tedersoo@ut.ee

L. Tedersoo

College of Science, King Saud University, Riyadh 11451, Saudi Arabia evaluation of records, with additional support from detailed anatomical observations and physiological data. We also identify common causes for errors, such as complex root anatomy in the Cupressaceae and Rosaceae. We also present detailed microscopic images of root structural features in trees with EcM or AM associations. Most AM roots have a suberised exodermis, which forms a permeability barrier around plant-fungus interfaces in the cortex and also protects roots from unwanted fungi. EcM short roots also have highly specialised anatomical features.

Conclusions Tree root atatomical features demonstrate convergent evolution that is presumably linked to more efficient and specific mycorrhiza formation. We recommend that future metastudies use corrected databases and new errors be avoided by using appropriate methodology and consistent definitions of association types.

Keywords Mycorrhizas · Trees · Northern hemisphere · Temperate forests $\cdot$ Horticulture $\cdot$ Root anatomy Diagnosis $\cdot$ Evolution

\section{Background}

The accurate identification of mycorrhizal associations in roots has recently become a major source of controversy (Brundrett and Tedersoo 2019; Bueno et al. 2019; Sun et al. 2019; Tedersoo et al. 2019). This is caused by a low but relatively consistent error rate in mycorrhizal trait (association type) data sets (Brundrett 2009), 
especially for arbuscular mycorrhizas (AM), ectomycorrhizas $(\mathrm{EcM})$ or nonmycorrhizal $(\mathrm{NM})$ roots. We have also noted that the most commonly sampled plants are more likely to have incorrectly allocated mycorrhizal traits in metastudies, because errors accumulate in databases if there are no error-detecting protocols. This can have a large impact on metastudies concerning the ecology or evolution of mycorrhizas that use these data compilations (Brundrett and Tedersoo 2019).

Here we focus on mycorrhizal associations of northern hemisphere trees, which are among the best studied, but also have a long history of misidentification (see below). These include the main species harvested for forestry from natural ecosystems or plantations and the trees which are most often planted in gardens and cityscapes. Our approach was to create an expert diagnosis using the consensus of data from the largest mycorrhizal trait database (FungalRoot, Soudzilovskaia et al. 2020), in combination with a thorough review of scientific studies on the anatomy and physiology of mycorrhizas. This diagnosis initially concerns the status of tree species and is extended to genera and families where data supports consistency at higher levels. This approach has also allowed us to suggest reasons for discrepancies between data provided by different observers. We also provide detailed microscopic illustrations of the mycorrhizal status of trees and anatomical specialisations of roots associated with AM or EcM associations. Our overall aim is to provide an authoritative and reliable diagnosis of mycorrhizas in Northern Hemisphere trees to resolve contradictions in earlier studies and avoid further errors and confusion, especially as a resource for the forestry and horticulture industries.

\section{Defining mycorrhizal associations}

One of the main sources of disagreement among mycorrhiza researchers concerns the fundamental definition of these associations, which has continued for $>120$ years and involves all mycorrhizal types (Koide and Mosse 2004; Trappe 2005; Brundrett 2004). Since the seminal works of Albert Bernhard Frank and Isobel Gallaud, mycorrhiza has been defined based on fungal structures inside root cells or on the surface of roots, that were linked to nutritional mutualism much later (Frank 1885; Gallaud 1905). After nearly a century, it became increasingly apparent that mycorrhizal fungi provide plants protection against stress and antagonists besides mineral nutrition (Smith and Read 2008) and that mycorrhizal plants and fungi belong to multiple, independently evolved, well defined taxonomic lineages (Kohout 2017; Orchard et al. 2017; Tedersoo and Brundrett 2017; Tedersoo and Smith 2017). This led to inclusion of the identity of mutualistic partners in the definition of EcM (Tedersoo and Brundrett 2017), especially as a means for excluding free-living or symbiotic root-associated fungi such as asymptomatic endophytes. In the continuum of fungal morphologies in roots, there are multiple examples, mostly from stressful environments, nursery-grown plants or unusual plantfungal combinations, where EcM structures are poorly developed (e.g. Malajczuk et al. 1987; Fortas and Chevalier 1992), but these rare exceptions rather prove the rule.

Standard definitions of mycorrhizal types are provided elsewhere (see Brundrett and Tedersoo 2018 - Box 1). Some authors have questioned the use of arbuscules and the Hartig net for defining AM and EcM, respectively (Bueno et al. 2019; Sun et al. 2019). However, this leads to a major problem, since discrediting the use of morphological definitions to define mycorrhizal associations also discredits how data in mycorrhizal databases and metastudies were originally obtained. Using arbuscules to define AM is required to distinguish mycorrhizal from endophytic activity (represented by vesicles and hyphae without arbuscules in roots) which is common in NM plants (Demars and Boerner 1996; Cosme et al. 2018) and EcM plants (Cázares and Trappe 1993; Wagg et al. 2008). AM fungi also commonly produce hyphae and vesicles in dead roots, decomposing leaves, old seeds, etc., but it is not clear if this is a form of necrotrophic interaction or if these fungi often seek shelter in soil organic materials (Aristizábal et al. 2004; Müller et al. 2017).

Attempts to find physiological definitions for mycorrhizas always fail because of the multifunctional roles of mycorrhizal fungi and the existence of myco-heterotrophic plants, so definitions of these associations must be based on anatomy (Brundrett 2004; Jones and Smith 2004). These definitions reflect the view of most mycorrhizal scientists and have gradually developed over more than a century (Koide and Mosse 2004; Trappe 2005). Here we advocate using standard morphological definitions supplemented with data on nutritional benefits and the detection of well-known symbiotic partners whenever such data are available (Tedersoo and 
Brundrett 2017; Brundrett and Tedersoo 2018). We see that roughly once or twice per year, potential cases of truly novel associations are reported (e.g., Orchard et al. 2017; Hoeksema et al. 2018). Therefore, it is wise to retain some flexibility in the scope of our definitions of mycorrhizas due to our current limited knowledge, especially from poorly sampled habitats. However, most unexpected reports of mycorrhizal associations that contradict other records for the same species or genera turn out to be errors, as we explain below.

Recognizing fungi that are not mycorrhizal in roots and interpreting their roles

Besides mycorrhizal fungi, nearly all vascular and non-vascular plants harbor root or rhizoidal associations with endophytes and saprotrophs that may display certain level of differentiation in the symbiotic interface and form resting structures such as vesicles and sclerotia (Mandyam and Jumpponen 2005; Smith et al. 2017; Fehrer et al. 2019). By definition, fungi as heterotrophic organisms are limited by energy and therefore, root exudates of plants may constitute an important supplement to their energy budget. Furthermore, plant roots offer protection from fungivores, which renders roots as a reliable habitat for storing energy supplies and dormant propagules (e.g. Müller et al. 2017). These interactions with endophytes and saprotrophs may be detrimental, neutral or beneficial to plants (Mandyam and Jumpponen 2005; Rodriguez et al. 2009).

Behaving as endophytes, mycorrhizal fungi often superficially colonize root surfaces and proliferate in the intercellular space or cell lumens of non-host plants. This activity is a consequence of their natural attraction to roots and the ability for mycorrhizal fungi to produce a suite of plant cell-wall degrading enzymes, although these vary between types of mycorrhizal fungi and are generally less diverse than those produced by wood decaying fungi (Giovannetti and Sbrana 1998; Kohler et al. 2015; Cosme et al. 2018). AM fungal hyphae on their own can be reliably identified in roots due to their characteristic appearance but also occur in non-host plants as endophytes, as explained above. Thus, it is necessary to use arbuscules as the key defining feature AM (e.g. Walker 1995; Brundrett 2009).
Unfortunately, many studies of tree roots have considered hyphae and vesicles of AM fungi without arbuscules in roots to be mycorrhizal, so cannot be relied on to confirm association types in databases (Brundrett 2009).

Some structurally undefined associations with fungi interpreted as mycorrhizal might be opportunistic, because molecular studies reveal abundant $\mathrm{AM}, \mathrm{EcM}$ and putative ericoid mycorrhizal fungi from roots of host plants exhibiting any of the three mycorrhizal types (Toju et al. 2014), which strongly conflicts with our understanding about plant-fungal functional associations in mycorrhiza. Although some nutrient exchange may occur without the typical mycorrhizal interface, the level of root colonization by arbuscules is strongly related to growth benefits and P uptake (Wilson and Hartnett 1998; Facelli et al. 2010; Manjarrez et al. 2010; Maltz and Treseder 2015). Furthermore, many plants that are regarded as NM, are commonly colonized by AM fungal hyphae, but display negative or neutral response to mycorrhizal fungi, and roots of NM plants can suppress germination and growth of fungal propagules and hyphae (e.g. Giovannetti et al. 1994; Grove et al. 2017). Waller et al. (2016) reported that colonization of only vesicles and hyphae may reduce the growth of weedy plant species. Some level of AM hyphal root colonization has often been observed in most species of Brassicales, but the crown group of this order lacks mycorrhizaassociated genes (Delaux et al. 2014). For these reasons, we consider the missing nutrient exchange structures indicative of non-mycorrhizal interactions. We also acknowledge that the fungal partners and functional roles also vary between different types of mycorrhizas, but these roles are usually not known when mycorrhizas are identified.

Fungi that are not mycorrhizal can enhance plant growth in semi-sterile soils (e.g. Varma et al. 1999; Ray et al. 2015; Rodriguez et al. 2009; Thoen et al. 2020), but it may not necessarily happen in nature where a wide functional diversity of soil microbes is already present. This probably explains why inoculation of AM plants with EcM fungi in artificial growing conditions can result in benefits without forming mycorrhizal associations. These experimental studies have included species of Fraxinus, Ulmus, Robinia, Malus, Prunus and Eucalyptus (Greene et al. 1982; Muhsin and Zwiazek 2002; 


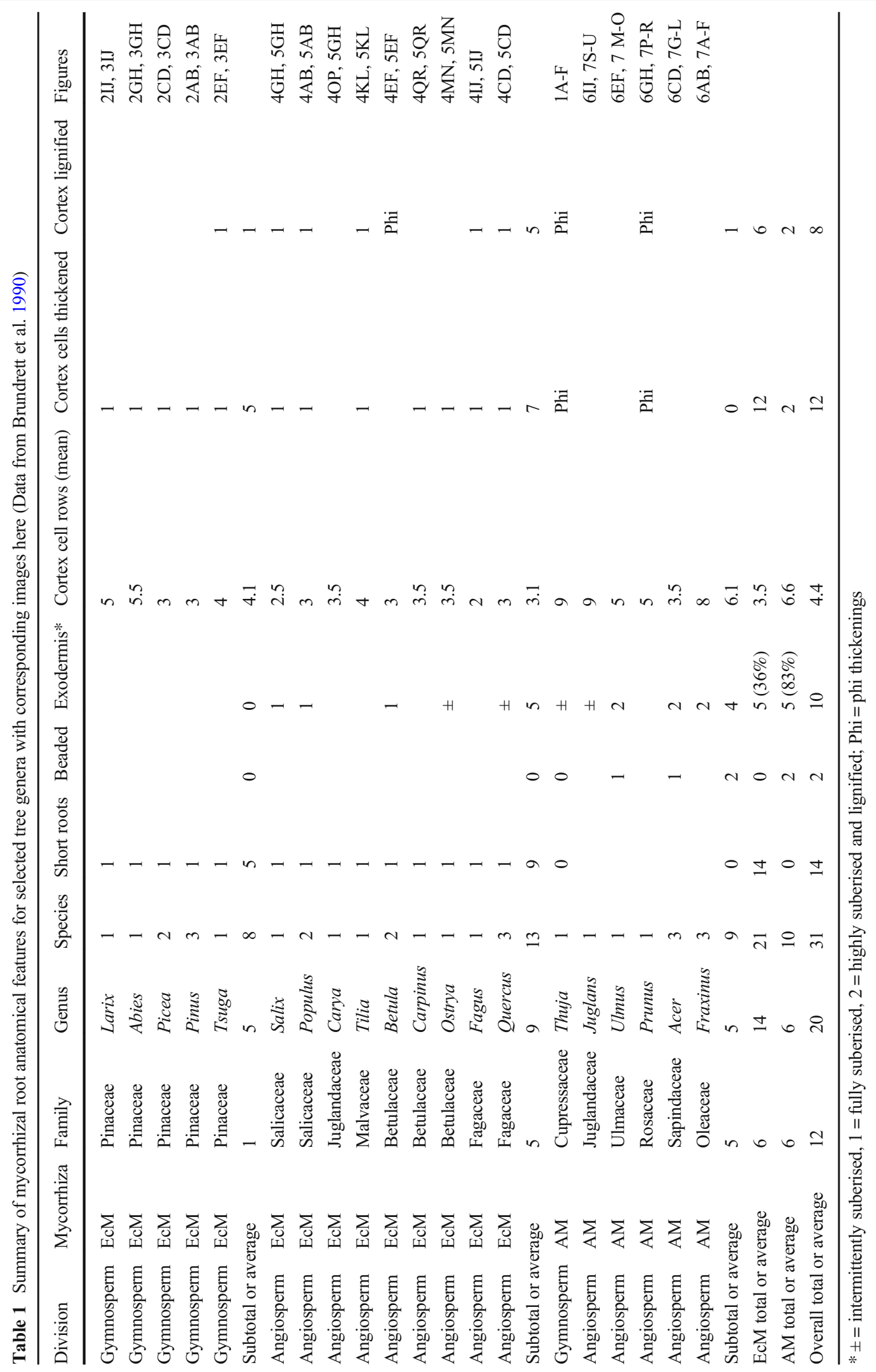


Polanco et al. 2008; Tian et al. 2003; Ambriz et al. 2010, Kariman et al. 2014; Murata et al. 2014). These associations fail to meet morphological definitions of mycorrhizal associations, involve unexpected fungi, or the evidence supplied is inadequate for accurate diagnosis (e.g. Ambriz et al. 2010;

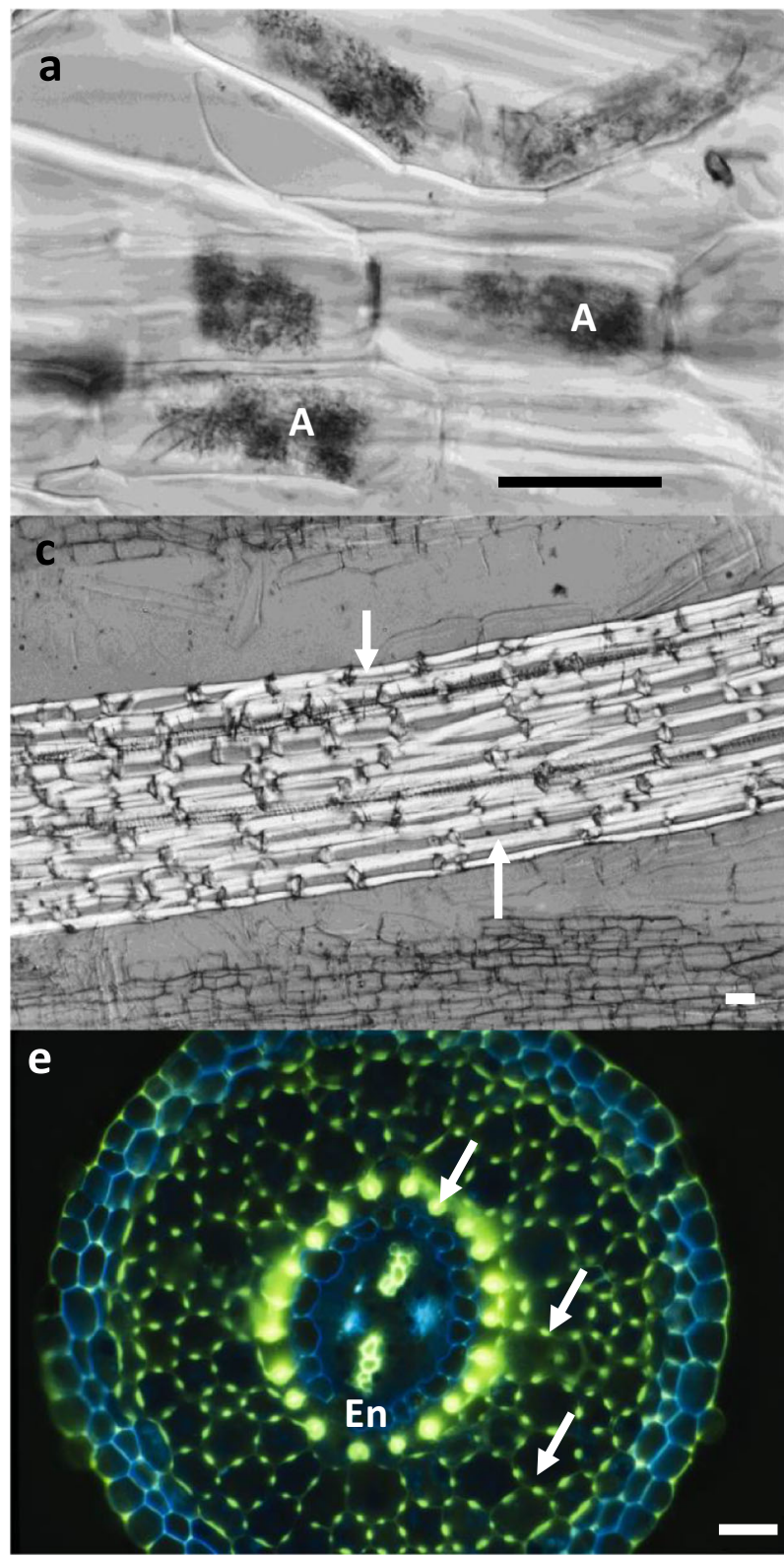

Fig. 1 Thuja occidentalis (White Cedar) a gymnosperm (coniferous) AM tree (scale bars $=50 \mu \mathrm{m}$ ). a-c. Hand crosssections or whole roots cleared in $\mathrm{KOH}$, stained with chlorazol black E and viewed with Nomarski interference contrast optics. a. Arbuscules in the root cortex (A). b. Vesicles in an older root (V). c. Inner-cortex phi thickenings (arrows) in a squashed root. d-f.
Muhsin and Zwiazek 2002; Thakur and Sharma 2013). We strongly recommend that the mycorrhizal status of plants be confined to associations that are known to occur naturally.

It is impossible to tell what fungi are doing based on some methods of detection, but it is common to assume
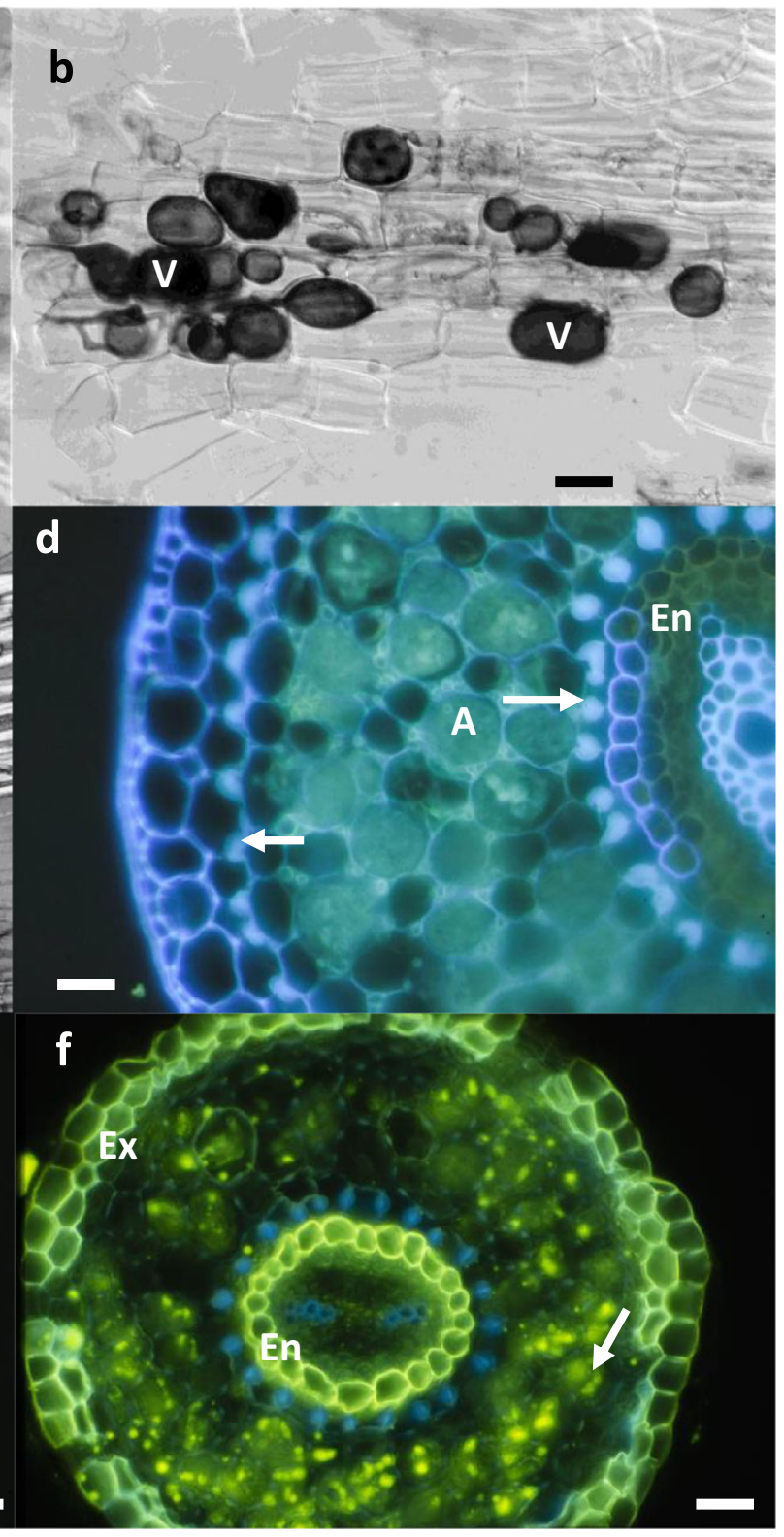

Florescence microscopy of hand cross-sections. d. Autofluorescence of xylem, phi thickenings (arrows), endodermal and exodermal cell walls. e. Berberine-Aniline Blue fluorescent staining of phi thickenings (arrows) and other features. f. Fluorol staining of suberin lamellae in the exodermis (Ex) and endodermis (En), and lipids in AM hyphae (arrows) 
that fungi detected in roots match the fungal clades known to form particular types of mycorrhizas. The issue of designating mycorrhizal vs endophytic root colonisation by fungi is further complicated by use of high-throughput DNA sequencing, which enables detection of fungi represented by a few hyphae on or in roots, which may be of limited consequence to plants (e.g. Toju et al. 2014; Selosse et al. 2018).

\section{Sources of errors in datasets}

Early data compilations acknowledged that many of the oldest data sources did not allow all types of mycorrhizas to be reliably distinguished, so simplify mycorrhizas down into fewer categories than are now recognized (e.g. Kelley 1950; Maeda 1954; Newman and Reddell 1987; Trappe 1987). However, this is not the case with many of the more recent data compilations which retrospectively assign older observations into newer categories of associations (we will provide a detailed analysis of this in a subsequent publication).

In addition to the situations where mycorrhizal fungi grow in non-host plants as discussed above, there are other factors that often seem to be linked to the misdiagnosis of fungal associations on roots. For AM plants, another source of misdiagnosis is caused by misidentification of saprotrophs and pathogens within roots as AM fungi. Although these fungi undoubtedly interact with and some may benefit plants, they are not mycorrhizal. Root endophytes, of which dark septate fungi are best known, form resting structures that are sometimes mistaken as AM (Mandyam and Jumpponen 2005). This situation is even more complicated in orchid and ericoid mycorrhizas, because the functional symbiotic fungi may be phylogenetically and functionally very closely related to taxa that commonly grow endophytically inside roots of other plants without forming coils (Kohout 2017; Selosse et al. 2018).

For EcM trees, incorrect diagnosis usually starts from a poor understanding of mycorrhizal root anatomy (Brundrett 2009, 2017; Tedersoo and Brundrett 2017). In particular, studies that disregarded the importance of the Hartig net and mantle, the defining features of EcM, need to be carefully evaluated (e.g. patches of hyphae on roots are misidentified as EcM in some cases). The second common cause for misidentification of EcM are the beaded fine roots of trees such as Acer spp. and the Ulmaceae and
Fig. 2 EM associations in short roots of gymnosperm (coniferous) trees showing Hartig net hyphae $(\mathrm{H})$. These are hand sections cleared in $\mathrm{KOH}$, stained with chlorazol black $\mathrm{E}$, and viewed with Nomarski interference contrast optics (scale bars = $50 \mu \mathrm{m}$ ). ab. Pinus strobus (white pine) cross section showing details of labyrinthine hyphae in the Hartig net. cd. Cross section of Picea mariana (Black Spruce) showing a labyrinthine Hartig net extending to the endodermis (arrows). EF. Tsuga canadensis (Hemlock) EM short roots. e. Cross section showing tannin-filled epidermal cells (E), thick-walled inner cortex cell (arrow) and Hartig net hyphae. f. Cross section of short root with Hartig net hyphae and haustoria of a parasitic fungus (arrows). gh. Abies balsamea (Balsam Fir) longitudinal sections of a short root with mantle and Hartig net hyphae, xylem, and refringent thick-walled inner-cortex cells (arrows). ij. Larix laricina (Larch, Tamarack) EM roots in tangential section with labyrinthine Hartig net hyphae surrounding cortex cells

Podocarpaceae. These feeder roots with short segments separated by constrictions superficially resemble EcM short roots. Some roots with complex anatomy, such as the Cupressaceae, some Rosaceae and some Fabaceae, include structures that superficially resemble a Hartig net (see below). The third common source of problems is caused by mixtures of species in samples. In many cases, it is possible to use anatomical features to identify tree roots of different species in samples from natural ecosystems (McDougall 1921; Brundrett et al. 1990). This would help resolve this source of errors in mycorrhizal data. The fourth cause of errors is reports of putative EcM fungi fruiting under trees where roots were not examined. The fifth common issue is that processing tree roots is technically more difficult than for herbaceous plants, because they tend to be long-lived, usually have a high phenolic content and are often heavily suberized and/or lignified (Brundrett et al. 1990). Clearing and staining methods for mycorrhizal assessment work best on young roots and short-lived plants, because secondary metabolites in old roots also have a high affinity for the stains used (Brundrett et al. 1996). Cross sections or longitudinal sections of roots can help to clarify complex root-fungus interactions, by allowing plant and fungal structures to be identified more precisely than in cleared roots.

\section{Detailed case studies}

This review provides a comprehensive assessment of the mycorrhizal status of selected trees using data from 

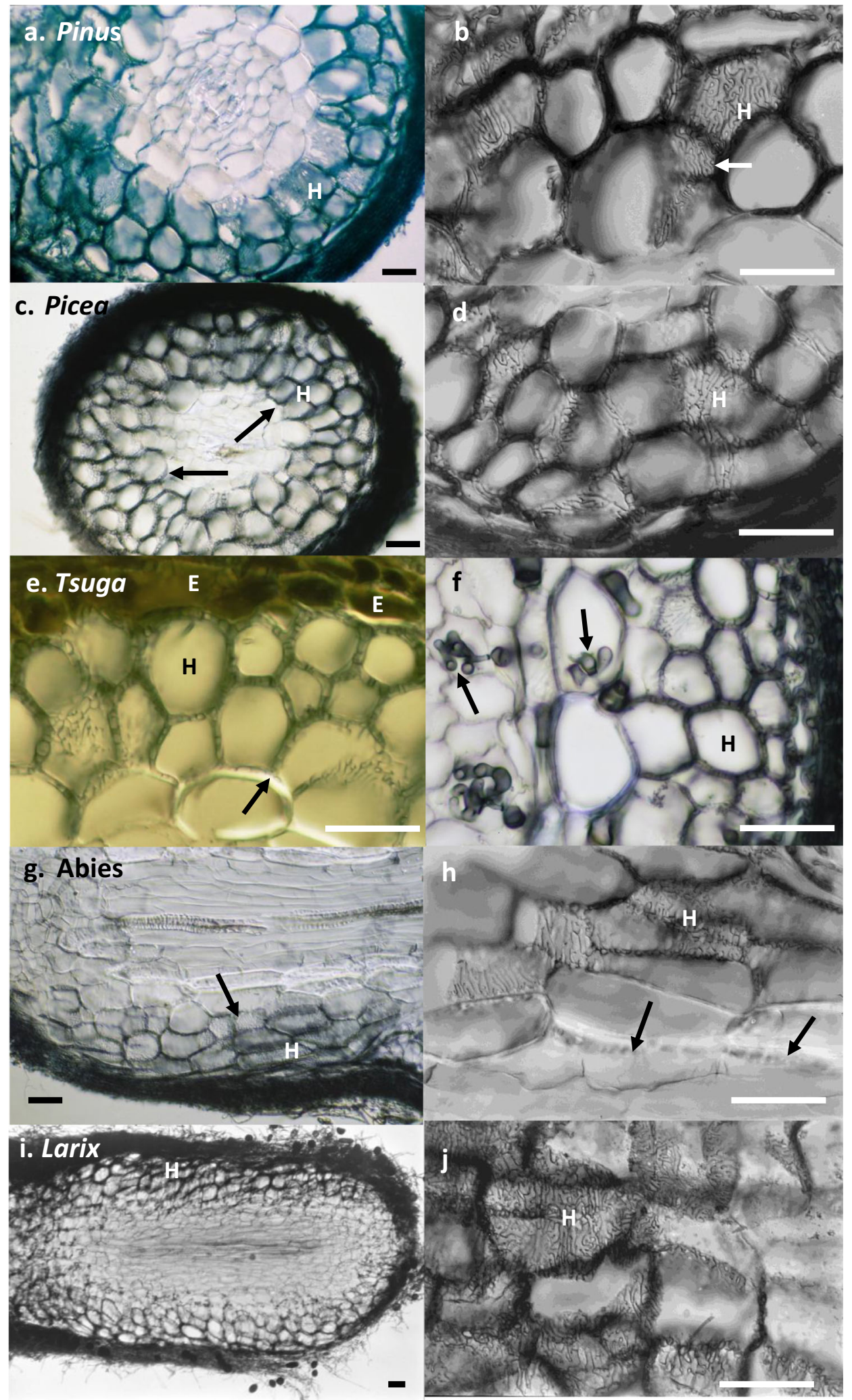
FungalRoot, the largest mycorrhizal traits database (Soudzilovskaia et al. 2020). This database is available via the PlutoF platform (https://plutof.ut. ee/\#/study/view/81127). For this study, the FungalRoot data was filtered to produce a smaller dataset of 3800 records for 940 relevant tree species, as summarised in Appendix Table 2. FungalRoot will be updated over time, but the version used in the current study is archived in GBIF (https://www.gbif. org/dataset/744edc21-8dd2-474e-8a0b-b8c3d56a3c2d).

Further evidence of the mycorrhizal status of trees is provided by detailed anatomical observations of the roots of representative species. These images include many of the tree genera where conflicting mycorrhizal data exist. The images and anatomical observations presented here are primarily from a comprehensive study of 40 species and 20 genera of Canadian trees, as listed in Table 1 (Brundrett et al. 1990). This study examined whole and sectioned roots by clearing in $\mathrm{KOH}$, followed by chlorazol black E staining and interference contrast microscopy to reveal mycorrhizal structures (Figs. 1, 2, 3, 4, 6, 7). Fluorescent histochemical stains (Brundrett et al. 1988, 1991) were also used to identify cell-wall composition of sectioned roots of the same species, (Figs. 1-3, 5, 6 and 7).

The status of the species with conflicting data was resolved using the protocols in Box 1. Mycorrhizal trait data for the majority of these species was consistent (66\% of species had no inconsistencies, $24 \%$ had a single outlier and $11 \%$ had multiple outliers). Data are summarised for genera where traits are consistent to avoid listing numerous species. As shown in Figs. 8, $9,10,11$ and 12 , there is a stark difference in mycorrhizal records between trees with EcM or AM symbioses, so these are dealt with in separate sections below. Trees are also separated into angiosperms and gymnosperms, with a separate section for additional species that are commonly grown in urban areas.

Figure 13 summarises the relative importance of trees with different mycorrhizal traits in North America and Eurasia using data from a global study (Soudzilovskaia et al. 2019). Using these data, total mycorrhizal tree biomass was calculated for selected areas of Eurasia and North America for all vegetation classes dominated by trees (Fig. 13). Out of the total vegetation biomass in Eurasia and North America ( 176 GT), AM trees constitute $43.9 \mathrm{GT}$, and EM trees constitute $67.6 \mathrm{GT}$ (Fig. 13b).
Box 1 To resolve contradictory, unexpected or unreliable mycorrhizal trait data, one or more of the following protocols was used

1. Forming a consensus view of trait status for species when the majority of data is in agreement ( $>90 \%$ of data sources concur for genera). Traits reported in a minority of cases are likely to either result from errors (within expected rates) or represent a secondary association type of minor significance.

2. Carefully checking traits that are in disagreement with the majority of data for a species by examining evidence used for diagnosis in data sources (if any is provided). In many cases these contradictory reports can be shown to be highly unlikely or impossible (see Tedersoo and Brundrett 2017 for case studies).

3. Identifying probable causes of diagnosis errors for families or genera where error rates are unusually high $(>10 \%)$. This requires knowledge of the structure of mycorrhizal roots and the habitats where they grow, as explained below.

4. Examining images published in detailed anatomical studies, or by obtaining new samples processed with appropriate staining methods to provide supporting information.

5. Comparing the status of closely related plants (usually within a genus) to reveal possible discrepancies and provide a diagnosis for unsampled or infrequently sampled species.

\section{Gymnosperm trees with AM roots}

In northern hemisphere habitats, AM gymnosperms account for about $15 \%$ of the living carbon stored in

Fig. 3 EM short roots of gymnosperm (coniferous) trees stained to reveal the Hartig net $(\mathrm{H})$ and anatomical features (scale bars = $50 \mu \mathrm{m})$. The fluorescent stains used are Berberine-Aniline Blue (BAB) for lignin and suberin and Fluorol for lipids. ab. Cross sections of Pinus strobus with fluorol staining of endodermal suberin lamellae and strengthened inner cortex walls (arrow). cd. Picea mariana short root cross sections. c. BAB staining of xylem and endodermal Casparian bands (En). d. Fluorol fluorescence of lipids in Hartig net hyphae and endodermal suberin lamellae (En). EF. Tsuga canadensis (Hemlock) root sections. e. Cleared and stained longitudinal section showing thick-walled inner cortex cell (arrow), and Hartig net hyphae (Nomarski interference contrast). f. $\mathrm{BAB}$ staining of endodermal cells and modified walls in innercortex cells (arrows). gh. Cross sections of Abies balsamea (Balsam Fir). g. Fluorol staining of endodermal suberin lamellae and resin duct cells (arrow), plus xylem autofluorescence. h. Chlorazol black E stained section showing cortex cells with thick refringent walls (arrows) and Hartig net hyphae (polarised light). ij. Cross sections of Larix laricina (Larch, Tamarack). i. Cross section showing BAB stained endodermis with Casparian bands and suberin lamellae, plus xylem. j. Unstained cross section with autofluorescence of Hartig net hyphae, inner cortex walls (arrows) and endodermal cell walls (En) 


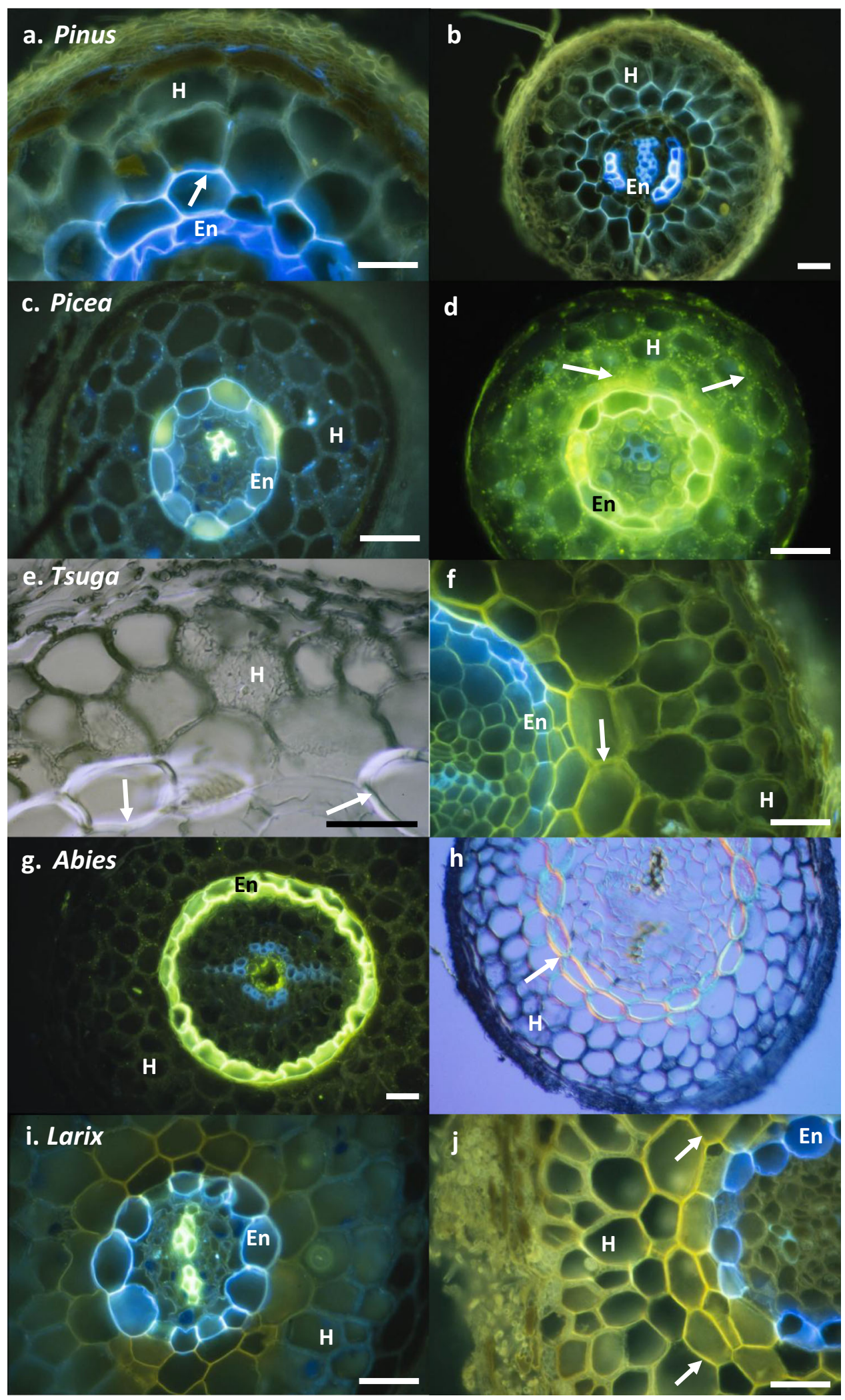


forests (Fig. 13). Data from 222 samples of 52 species in three families are included here (Appendix Table 2). AM associations are very well documented in roots of genera such as Juniperus, Cupressus and Taxus in the Cupressaceae and Taxaceae, as well as Gingko biloba in the Ginkgoaceae (Fig. 8). AM associations in these roots are similar in structure to those in angiosperms, but there are some major differences in their root anatomy (Fig. 1). AM associations have been shown to substantially improve growth of Thuja, Calocedrus, Sequoia, and Sequoiadendron species in soils with low phosphorus availability (Kough et al. 1985). Despite some early confusion, AM associations have also been well documented in southern hemisphere conifer genera such as Agathis and Araucaria (Araucariaceae), as well as Podocarpus (Podocarpaceae) (Padamsee et al. 2016; Dickie and Holdaway 2011). Both Ginkgo and Podocarpus species have beaded roots and the anatomy of their AM associations has been described in considerable detail (Fontana 1985; Bonfante-Fasolo and Fontana 1985; Dickie and Holdaway 2011).

We suspect that one reason for the relatively high frequency of false reports of EcM in Juniperus compared to other AM conifers is that their roots often grow intermingled with those of pines, which can extend $>20 \mathrm{~m}$ from a tree trunk. Furthermore, roots of Juniperus spp. and other Cupressaceae have phi thickenings of some cell walls in their cortex forming prominent rectangular patterns that probably have been misidentified as a Hartig net by some observers (see Fig. 1c, e). These anatomical structures occur in the roots of all the AM conifers in the Ginkgoaceae, Araucariaceae, Taxaceae, and Cupressaceae that have been examined (41 species) and their formation has been linked to growth in stressful habitats (Gerrath et al. 2002).

\section{Gymnosperm trees with EcM roots}

The Pinaceae family primarily consists of evergreen trees from temperate regions and includes about 250 species in 11 genera (wikipedia.org accessed 16-8-2019). These trees account for $40 \%$ of the living carbon stored in northern hemisphere forests (Fig. 13). There are close to 1000 records of EcM roots in the FungalRoot database for 155 species in seven genera of the Pinaceae (Figs. 2 and 8). The EcM habit in gymnosperms is restricted to Gnetum (Gnetaceae) and the Pinaceae (Brundrett and Tedersoo
Fig. 4 EM associations in short roots of angiosperm trees illustrating the Hartig net $(\mathrm{H})$ and other features. The left images are whole mounted roots or longitudinal sections and images on the right are cross sections. These are cleared in $\mathrm{KOH}$, stained with chlorazol black E, and viewed with Nomarski interference contrast optics to show the Hartig net $(\mathrm{H})$ and mantle hyphae (scale bars = $50 \mu \mathrm{m})$. ab. Populus tremuloides (Trembling Aspen). a. Whole root. b. Labyrinthine Hartig net with hyphal pegs (inset) and thick exodermal (Ex) and cortex walls (arrows). cd. Quercus velutina (Black Oak). c. whole root. D. quercus rubra (Red Oak) showing xylem, endodermal Casparian bands (En), very thick cortex walls (arrows) with pits, epidermal Hartig net and mantle. ef. Betula papyrifera (White Birch). f. EM root with Phi thickenings in cortex cells (arrows). gh. Salix nigra (Black Willow). h. Mantle and incomplete epidermal Hartig net. ij. Fagus grandifolia (Beech). i. longitudinal section. j. Hartig net hyphae. kl. Tilia americana (Basswood). k. longitudinal section. I. Mantle and epidermal Hartig net. mn. Ostrya virginiana (Hop Hornbeam). m. Whole root. n. Hartig net and thick-walled cortex cells (arrows). op. Carya ovata (Shagbark Hickory). o. Longitudinal section of Hartig net. p. Unstained cross section (polarised light) showing Hartig net and large druse crystals in cortex (arrows). qr. Carpinus caroliniana (Blue Beech). q. Whole root. r. Hartig net hyphae which have penetrated into epidermal cells to form ectendomycorrhizas (inset)

2018). These species (except Gnetum) all have highly branched short roots and Hartig net hyphae that extend well into the root cortex (Fig. 2). The Hartig net of Tsuga, Abies and Larix species is excluded from the inner cortex by one or more layers of cells with thickened cell walls, as illustrated in Fig. 3. AM fungi sometimes occur in roots of these plants (Horton et al. 1998; Cázares and Trappe 1993; Wagg et al. 2008), but primarily as vesicles and hyphae in seedlings, so their presence should be designated as endophytic activity.

As shown in Fig. 9, there is a relatively low error rate for mycorrhizal records in this family compared to the angiosperm trees with EcM discussed below. These errors are highly correlated with sample numbers per genus, which suggests they are due to issues with methodologies used to study roots rather than the species of tree or its habitat (Fig. 9b). It has been well documented that the Pinaceae generally will not grow into adult trees in the absence of compatible EcM fungi, which have codispersed with them to exotic locations all over the globe (Nunez et al. 2009; Dickie et al. 2010, 2017).

\section{Angiosperm trees with EcM roots}

Ectomycorrhizal angiosperms account for about $30 \%$ of the living carbon stored in northern temperate forests 


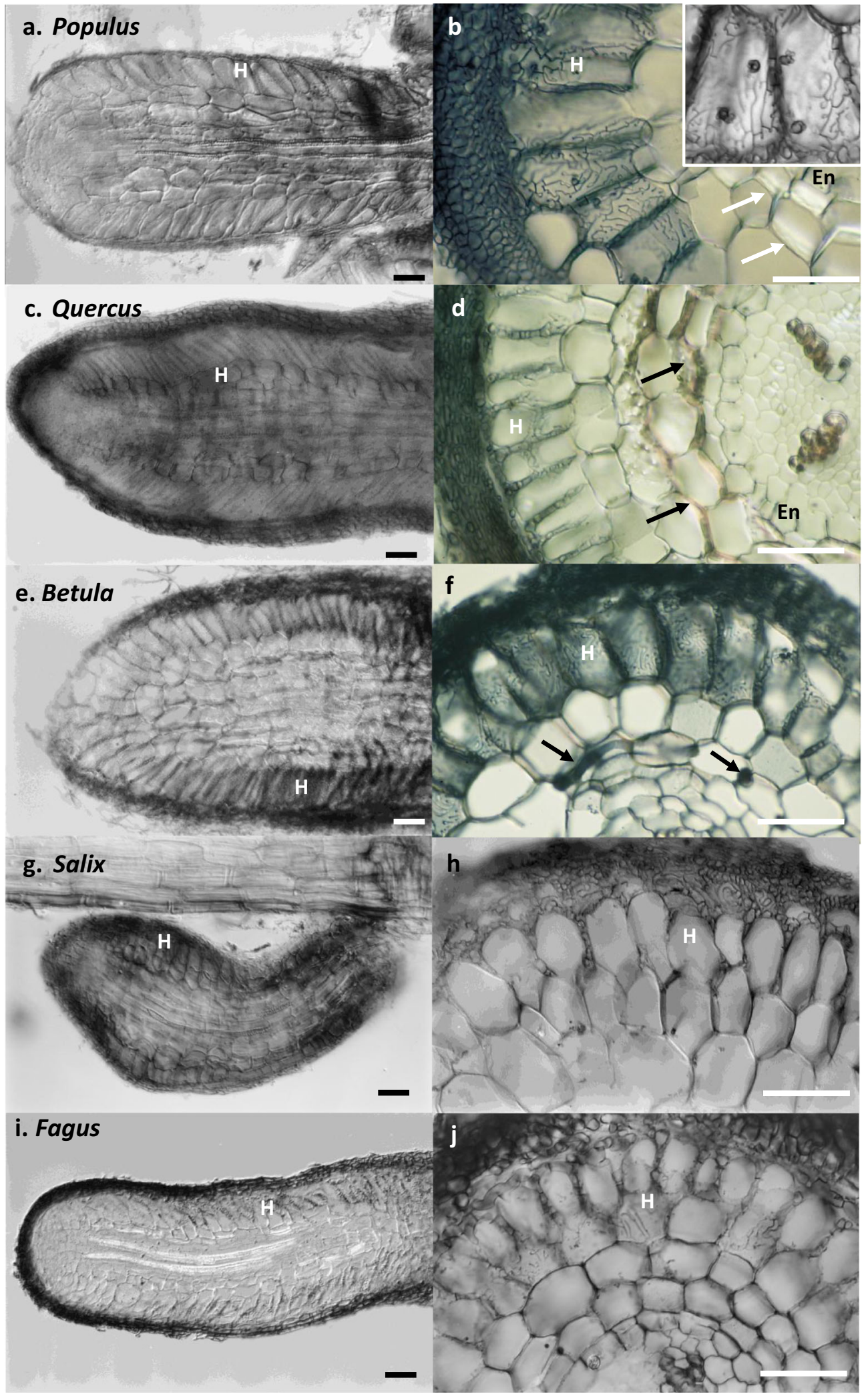




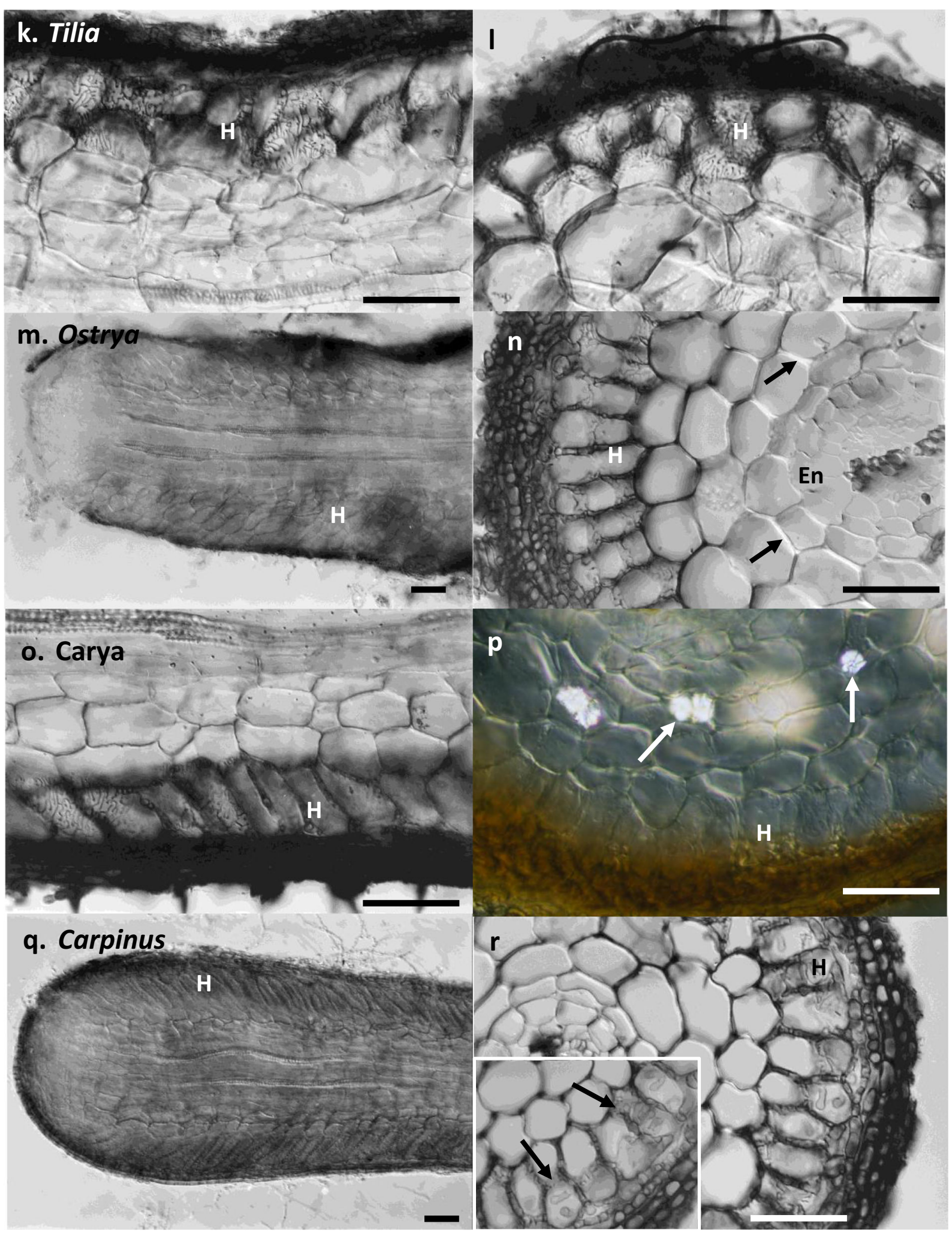

Fig. 4 (continued) 
(Fig. 13). Data from four families, 13 genera, 295 species and about 1500 samples are summarised here. Members of the Ericaceae with EcM are not discussed here since most are not large trees (Arbutus, Arctostaphylos, etc.).

Fagus, Quercus and related Fagaceae

The literature includes many reports of EcM only in roots of these trees, as is summarized in Fig. 10, and this has been also well documented in earlier reviews (Trappe 1987; Harley and Harley 1987; Brundrett et al. 1990). The structure of these roots is highly specialised for EcM formation as illustrated in Fig. 4. However, there also are some discrepancies in the literature, such as the reports of EcM and AM by Bainard et al. (2011), who did not confirm the presence of arbuscules. It is likely that all reports of AM associations in the Fagaceae represent endophytic activity, but more careful observations are required in some genera, especially Castanopsis, which has more reports on AM than expected. Species of this genus usually grow in AMdominated subtropical forests, so root contamination of samples is one likely cause of these records.

\section{Alnus, Corylus and Betula (Betulaceae)}

The Betulaceae incudes about 170 species of deciduous trees and shrubs in the genera Alnus (alder) and Betula (birch) in the Betuloideae subfamily and Carpinus (hornbeam), Corylus (hazel), Ostrya (hop-hornbeam) and Ostryopsis in the Coryloideae subfamily (Figs. 4, 5, 10). Like other members of the Fagales such as Fagus and Quercus (Section E), all these trees have predominantly EcM associations with AM also reported in some cases (Tedersoo and Brundrett 2017). Alnus can form AM with arbuscules in very cold soils (Kilpeläinen et al. 2016), but it has fewer records of AM than most other EcM-AM trees. Alnus species also have actinorhizal nitrogen fixing associations with root nodules containing Frankia species (Russo 2005). Corylus EcM is well documented as one of the hosts of truffles (Tuber spp.), including detailed genomic, biochemical and structural studies (e.g. Benucci et al. 2012; Sillo et al. 2016; Hacquard et al. 2013). Betula EcM roots are characterized by an epidermal Hartig net above three rows of cortex cells with Phi thickenings (Figs. 4f and 5ef).

Salix, Populus (Salicaceae)

The genus Salix includes about 400 deciduous trees and shrubs and Populus includes about 30 tree species, both primarily found in cool climates. Both EcM and AM associations in Populus and Salix trees have been commonly reported, but experimental studies show EcM to be dominant over AM in most situations (Lodge 1989; Khasa et al. 2002; Beauchamp et al. 2006; Gehring et al. 2006; Becerra et al. 2009). Furthermore, the role of AM may be less important than expected as hyphae and vesicles only were reported by Malloch and Malloch (1981) and many other studies did not report arbuscular colonization separately from hyphae and vesicles, so cannot be used to confirm AM. Populus sp. roots have a Hartig net that develops on greatly elongated epidermal cells (Figs. 4ab and 5ab). Salix also has a much higher incidence of reports of EcM than AM roots in FungalRoot, but has also occasionally been reported to be NM (Fig. 10). Nonmycorrhizal roots are only very rarely observed in Salix plants growing in permanently flooded habitats (LT unpublished data). Salix EcM roots have some structural features that seem to be relatively primitive, such as long, unbranched short roots with more rows of cortex cells and a fully suberised exodermis (Table 1).

\section{Tilia species (Malvaceae)}

The majority of records for Tilia spp. are for EcM only (57 records), but there are also four reports of AM and a single report of NM roots we consider to be errors (Fig. 10). We have observed that Tilia sp. roots are very heavily colonized by EcM fungi, relative to members of the Salicaceae and Betulaceae. McDougall (1914) list Tilia americana as EcM, as do Sen and Jenik (1962) who conducted a detailed anatomical study of T. europea. Harley and Harley (1987) list 10 reports of EcM in T. europea and two of endomycorrhizas from the 1950's - before modern definitions of mycorrhizas were in use. Brundrett et al. (1990) carried out detailed anatomical studies and also reviewed all existing data and designated T. americana as EcM only. Tilia roots have highly specialised anatomical features similar to those of other angiosperm EcM trees (Figs. 4kl and 5kl).

\section{Angiosperm trees with AM roots}

These trees account for about $15 \%$ of the living carbon stored in northern temperate forests. Data from over 1000 samples from 364 species in 18 families and 32 genera are summarised here (Appendix Table 2). Families are presented separately since the structure of 
mycorrhizal roots and issues with data consistency differ considerably.

\section{Fraxinus and Olea (Oleaceae)}

The genus Fraxinus contains 45-65 species of usually deciduous temperate or subtropical trees and Olea contains about 33 species of evergreen trees or shrubs from warm temperate or tropical areas (wikipedia.org, accessed 16-8-2019). There are many records of AM in Fraxinus and Olea species (53 for Fraxinus and 18 for Olea) and five reports of EcM or NM roots for Fraxinus (Fig. 10). Some early records of EcM in Fraxinus spp. are due to observations of the fungus Gyrodon merulioides fruiting under these trees, but this bolete has since been found to associate with aphids on ash tree roots, so it is not mycorrhizal (Brundrett and Kendrick 1987). Brundrett and Kendrick (1988) looked at 171 samples of Fraxinus americana collected throughout the year and only found AM. The experimental study by Ambriz et al. (2010) where the EcM fungus Pisolithus tinctorius was used to inoculate Fraxinus uhdei should not be used as conclusive evidence for EM since they combined organisms that may not associate together in nature in a simple system and they do not provide adequate images for diagnosis. An experimental study by Chenchouni et al. (2019) measured substantial growth responses to AM fungi in olive trees (Olea europaea).

Detailed anatomical images of Fraxinus roots are shown in Figs. 6 and 7. Young Fraxinus spp. roots contain numerous arbuscules and convoluted hyphae within unusually wide linear cortex air spaces. These roots also have a dimorphic exodermis (with long and short cells), an anatomical specialisation to protect roots from unwanted fungi and facilitate efficient nutrient exchange with AM fungi (see below). The combination of root anatomy and AM morphology of Fraxinus spp. roots are highly distinctive, when compared to other plants they commonly grow with.

Acer (Sapindaceae) and Ulmus (Ulmaceae)

These are deciduous trees that primarily occur in temperate regions, with about 130 species of Acer (maples) and about 35 species of Ulmus (elms) recognized. Here we consider these trees together since they have similar root anatomy due to convergent evolution (Figs. 6ef and $7 \mathrm{~m}-\mathrm{o})$. As shown in Fig. 10, most records are of AM, but there are some reports of EM, which we consider to be errors. Aesculus species (Sapindaceae) also have AM in beaded roots (Khan 1972; Kinden and Brown 1975). As explained above, the main reason for reports of EcM in Acer and Ulmus species, seems to be that these trees have beaded roots (see Fig. 7g), which can be confused with EcM short roots (Fig. 14). Roots of these trees are also very difficult to clear and stain effectively due to abundant cell wall depositions of suberin, lignin and tannins that make older stained whole roots opaque (Brundrett et al. 1990). As discussed further below, both Acer and Ulmus roots have lignified outer cell walls in their exodermis and epidermis that would prevent EcM fungi from forming an effective association (Fig. 7a-o).

Malus, Pyrus, Prunus, Sorbus, etc. (Rosaceae)

There are 226 records of AM for in Crataegus, Malus, Prunus, Pyrus and Sorbus (Figs. 10 and 12). However, there are also 47 reports of EcM and a few of NM which we consider to be errors (see Tedersoo and Brundrett 2017, Fig. 11). A detailed anatomical study and review of the literature found Prunus spp. to consistently have AM (Brundrett et al. 1990). The Rosaceae and other trees with complex roots have higher than expected rate of mycorrhizal diagnosis (Fig. 14). As is the case with AM conifers, they have phi thickenings (Weerdenburg and Peterson 1983; Brundrett et al. 1990). These form prominent rectangular grid patterns in roots that may have been mistaken for a Hartig net in the past (Figs. 7p-r).

Detailed investigations of apple roots sampled from 18 states in the US found only AM associations (Miller et al. 1985). A literature search for apple trees (Malus sp.) in Google Scholar (TM) finds close to 100 studies of AM including experiments showing substantial growth responses to inoculation (e.g. Berta et al. 1995), but there have also been attempts to inoculate these trees with EcM fungi (e.g. Thakur and Sharma 2013). Murata et al. (2014) found that Tricholoma matsutake formed endophytic interactions with Prunus speciosa that promoted plant growth in vitro, but EcM roots were not formed. We believe it is incorrect to designate Malus as an EcM species (even in part) since there is no reliable evidence that EcM fungi form mutualistic associations with apple trees in nature. 

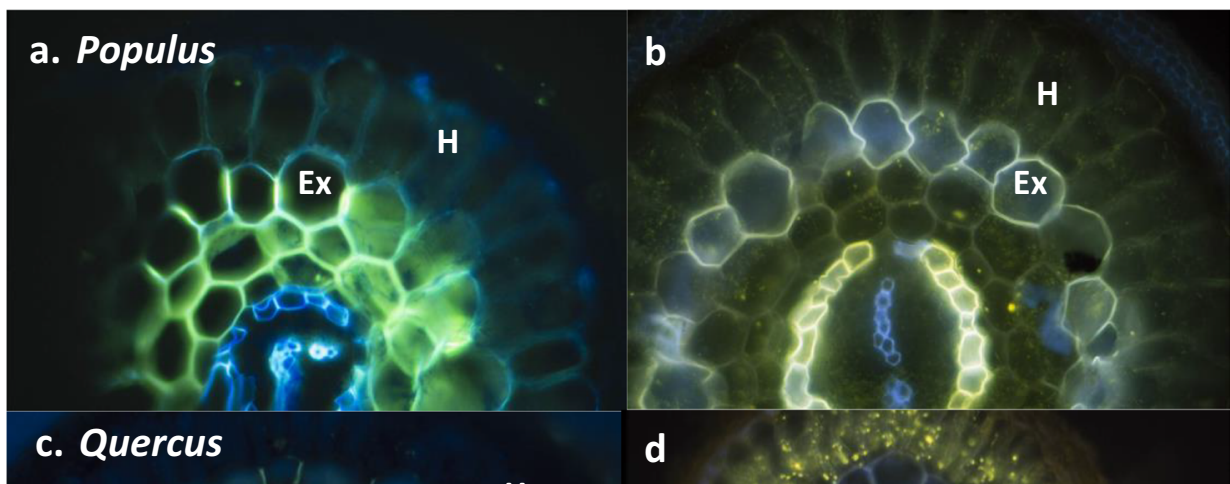

\section{c. Quercus}

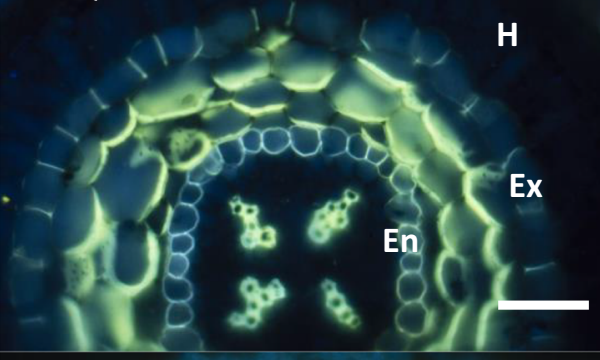

e. Betula

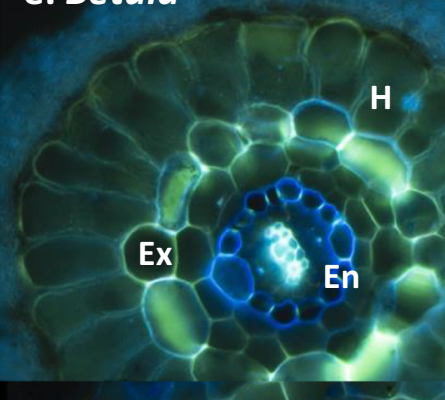

g. Carya

H

H

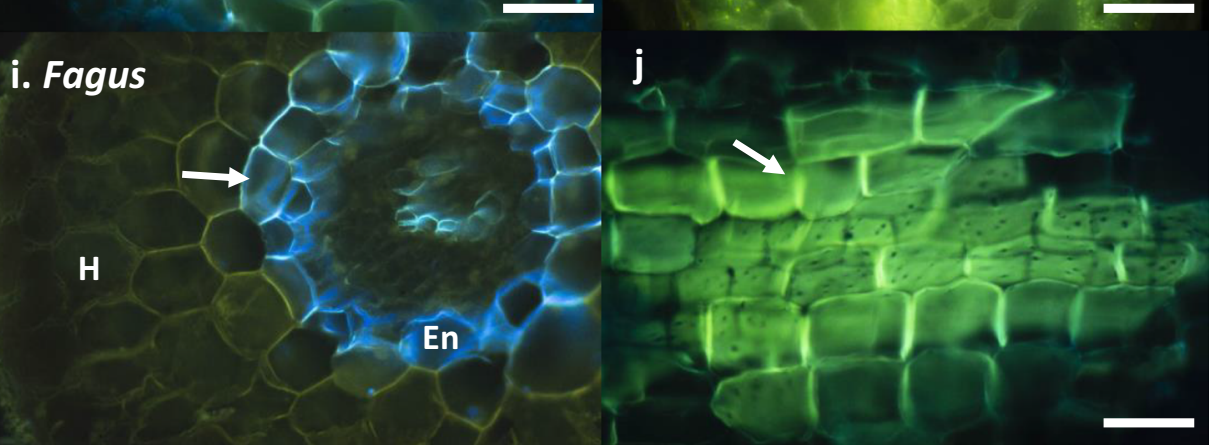




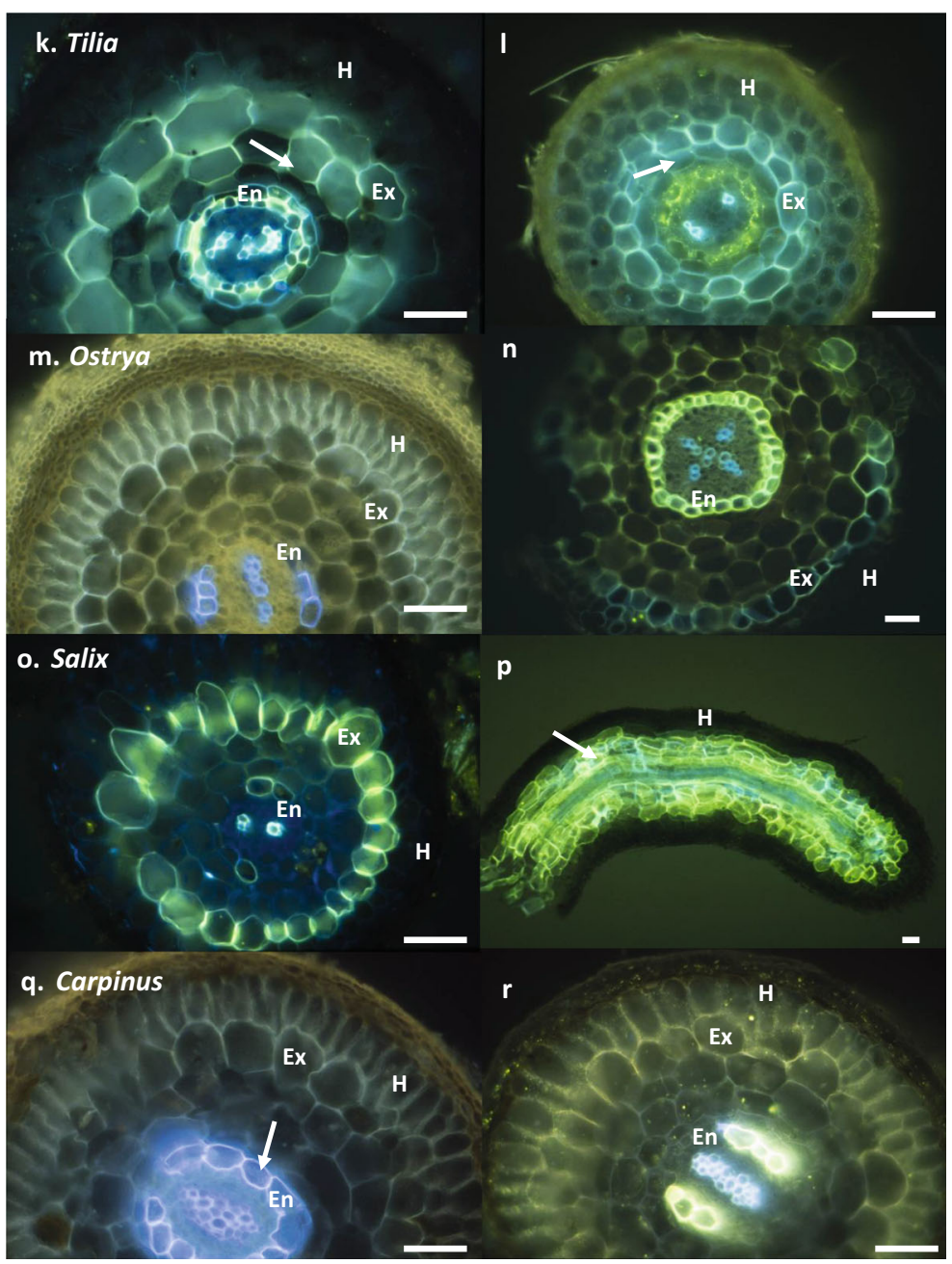

Fig. 5 EM short roots of angiosperm (deciduous) trees that have been hand sectioned and stained with fluorochromes to reveal anatomical features and the Hartig net $(\mathrm{H})$. Most of these cross sections are stained with Berberine-Aniline Blue (BAB), or the lipid stain Fluorol and viewed using fluorescence microscopy (scale bars $=50 \mu \mathrm{m}$ ). ab. Populus species. a. Populus balsamifera (Balsam Poplar) BAB stained section showing thick inner cortex cell walls (arrows). b. Populus tremuloides (Trembling Aspen) with Fluorol staining of endodermal and exodermal suberin lamellae and lipids in Hartig net hyphae (arrows). cd. Quercus species. c. Quercus alba (White Oak) with BAB staining of exodermal Casparian bands, cortex sclerenchyma (arrows), endodermis and xylem. d. Quercus rubra (Red Oak) with fluorol staining of endodermal suberin lamellae and lipids in Hartig net hyphae (arrows). ef. Betula species. e. Betula papyrifera (White Birch) with BAB staining of exodermal Casparian bands, as well as the endodermis and xylem. f. Betula alleghaniensis (Yellow Birch) EM with BAB staining of phi thickenings (arrows), endodermal suberin, and xylem. gh. Carya ovata (Shagbark Hickory). g. BAB staining of xylem, endodermal Casparian bands and suberin lamellae. h. Fluorol staining of endodermal and exodermal suberin lamellae. ij. Fagus grandifolia (Beech). i. BAB-induced fluorescence of xylem, endodermal Casparian bands, cortex cell innerwall thickenings (arrows), and hypodermal cells. j. longitudinal section of cortex with BAB staining of lignified cell walls. kl. Tilia americana (Basswood). k. BAB staining of xylem, suberin in the endodermis and pericycle and modified cortex walls (arrows). $\mathbf{L}$. Fluorol staining of exodermal suberin and lipid droplets in immature endodermal cells (arrows). mn. Ostrya virginiana (Hop Hornbeam). m. Autofluorescence of Hartig net hyphae and root structures. n. Fluorol staining of endodermal and exodermal Casparian bands. op. Salix nigra (Black Willow). o. BAB-stained exodermal Casparian bands (arrows). P. Longitudinal section showing Fluorol staining of suberin lamellae in the exodermis. qr. Carpinus caroliniana (Blue Beech). q. Autofluorescence of Hartig net hyphae, the endodermis (arrow) and xylem. R. Flurol staining of endodermal and exodermal cells (arrows) and lipids in Hartig net hyphae 


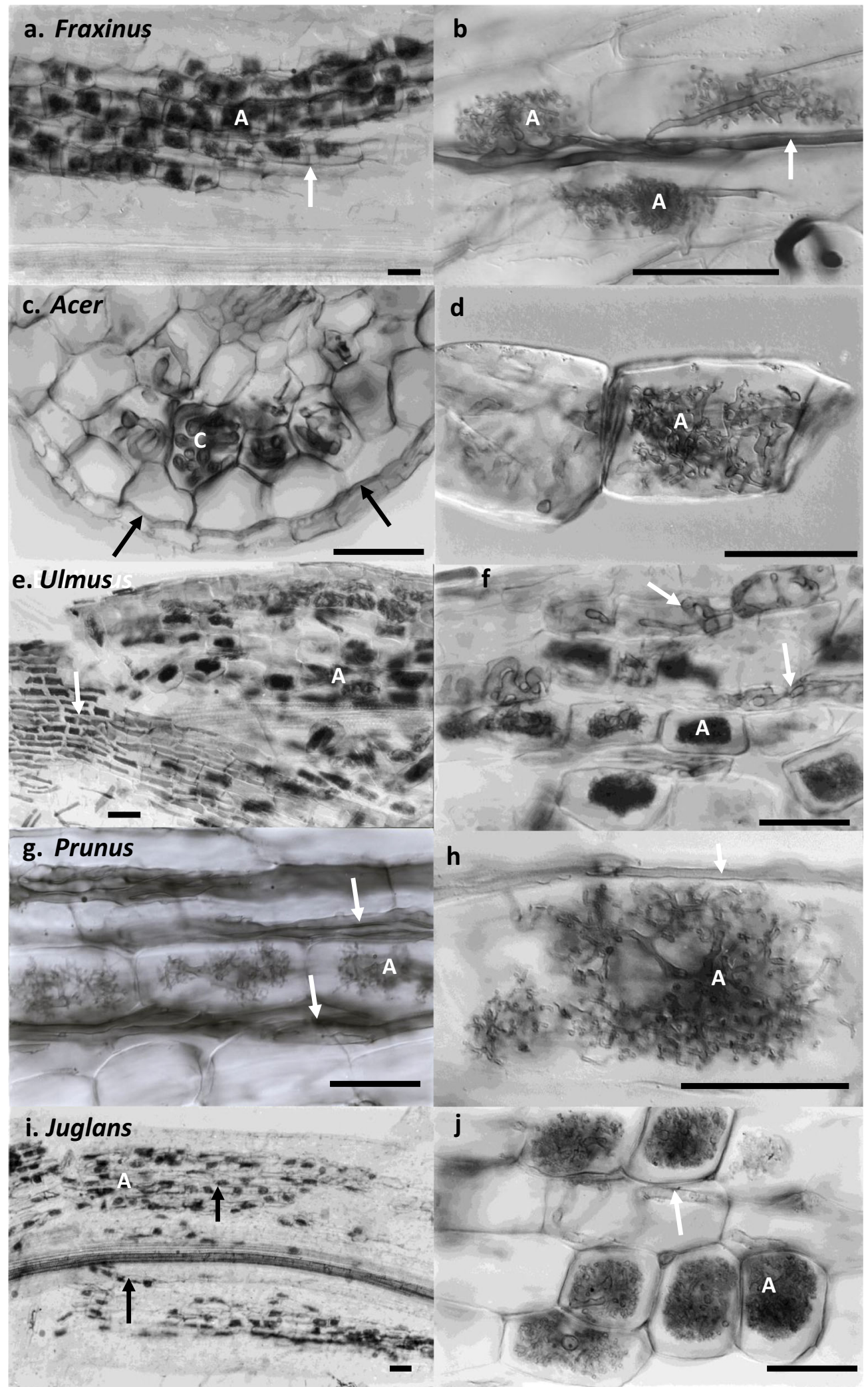


Fig. 6 AM associations in roots of angiosperm trees. These are whole roots or hand sections cleared in $\mathrm{KOH}$, stained with chlorazol black E, and viewed with Nomarski interference contrast optics (scale bars $=50 \mu \mathrm{m}$ ). ab. Fraxinus americana (White Ash) whole roots with linear hyphae following air channels (arrows) and numerous arbuscules (A). c. Acer rubrum (Red Maple) root cross section with hyphal coils and very thick outer exodermal walls (arrow). d. A. saccharum (Sugar Maple) arbuscules. ef. Ulmus americana (White Elm) roots squashed to reveal hyphal coils (arrows), arbuscules (A) and tannin-filled epidermal cells (E). gh. Prunus serotina (Black Cherry). g. Convoluted intercellular hyphae in wide cortex air channels (arrows). H. Arbuscules with numerous fine branches (A). ij. Juglans nigra (Black Walnut) root with linear AM hyphae (arrows) and numerous arbuscules (A)

\section{Robinia, Gleditisa, etc. (Fabaceae)}

Trees in this family from temperate northern habitats have relatively high error rates for mycorrhizal diagnosis (Fig. 10), but there is no conclusive evidence for anything but AM in their roots (Tedersoo and Brundrett 2017). A detailed structural study by Kovács et al. (2003) of Robinia pseudoacacia inoculated with Terfezia (Mattirolomyces) terfezioides (a fungus now considered to be nonmycorrhizal) concluded that this fungus colonised roots but did not form associations that could be designated as EcM and also did not promote growth. Many trees in the Fabaceae have more complex relationships with mycorrhizal fungi (EcM or EcM and $\mathrm{AM}$ ), but these tend to occur in warmer regions or the southern hemisphere (Tedersoo and Brundrett 2017).

\section{Mycorrhizas of commonly grown ornamental trees}

Figure 12a and Appendix 1 include data from some additional genera of commonly planted street trees in temperate areas as a resource for horticulture industries. Data on popular urban tree genera with EcM such as Betula, Populus and Quercus and coniferous AM trees such as Juniperus, Cupressus, Taxus and Ginko are presented above. Most of the trees in Fig. 12 also have a few records that contradict the majority of data (EcM or NM) that are highly likely to be errors. There was a strong linear relationship between number of records and conflicting data for street trees showing that the mycorrhizal diagnosis error rate was similar across all these genera (Fig. 12b). Overall, there is overwhelming support for the AM status of all these trees (79\% of records).
Fig. 7 Microscopic images of AM associations in roots of angiosperm trees stained to reveal anatomical features (scale bars = $50 \mu \mathrm{m}$ ). The fluorescent stains are Berberine-Aniline Blue (BAB) for suberin and lignin and Fluorol for lipids (uv fluorescence). a-f. Fraxinus americana (White Ash). a. Whole roots with aphid-containing sclerotia attached (arrow). b. Cross section of root with BAB-induced fluorescence of xylem, endodermal (En) and exodermal walls (Ex). c. Fluorol staining of endodermal and exodermal suberin lamellae, as well as lipids in hyphae. de. Chlorazol black E stained whole root with Metacutinized root cap (M) and suberised exodermis with short cells (*). f. Fluorol staining of exodermal suberin lamellae showing a passage cell where AM fungi have entered (arrow). g-l. Acer saccharum (Sugar Maple). g. Whole roots of Acer saccharinum (Silver Maple) showing prominent beads (arrows). h-k. Anatomical details of Acer saccharum roots. $\mathbf{h}$. Cross section with autofluorescence of exodermal cells with thick outer walls (arrows), xylem and endodermal Casparian bands. i. Longitudinal section of beaded root stained with Fluorol to show suberin deposition (arrows) around the apical meristem (metacutinization). j. Prominent epidermal and exodermal cells in roots cleared and stained with Chlorazol black E. k. Cross section of a young root with BAB-staining of the exodermis with thick outer walls (arrows), xylem, endodermal Casparian bands and phloem sieve tubes (arrow). I. Acer saccharinum root cross section with fluorol stained suberin lamellae in exodermal cells and lipids in AM hyphae (arrows), as well as endodermal suberin lamellae. m-o. Ulmus americana (White Elm). m. Cleared and stained short root with swollen base and narrow tip that is resuming growth (arrow). n. Root cross section (BAB) showing exodermis (Ex), endodermis (En) and cortex walls. o. Longitudinal section with Fluorol staining of exodermis, endodermis and lipids in AM fungal hyphae (arrows). p-r. Prunus serotina (Black Cherry). p. Phi thickenings (arrows) are very apparent in whole cleared and stained roots (polarised light). q. Cross section with endodermal suberin lamellae revealed by Fluorol fluorescence. Autofluorescence of phi thickenings (arrows) and xylem can also be seen. r. Similar section with BAB stained xylem, endodermal Casparian bands and phi thickenings (arrows). s-u. Juglans nigra (Black Walnut). s. Unstained section with polarised light-induced refringence of crystals (arrows) and xylem cell walls. t. BAB staining of endodermal cells and AM fungi in the cortex. u. Fluorol staining of suberin lamellae of the endodermis and hypodermis, as well as lipids within AM hyphae (arrows)

This provides further support to our theory that the misdiagnosis of mycorrhizas is primarily due to issues with methods used to study roots, since errors were not well correlated with plant identity or habitats.

Bainard et al. (2011) found AM fungi in the roots of 26 species of street trees including species of Acer, Fraxinus, Robinia, Aesculus and Thuja, as well as EcM in Betula, Populus and Quercus. However, they failed to distinguish mycorrhizal from endophytic activity by AMF, so incorrectly reported AM in a few EcM trees. A similar situation occurs in the Platanaceae (Proteales), which includes a single genus Platanus with eight species, some of which are important cultivated 


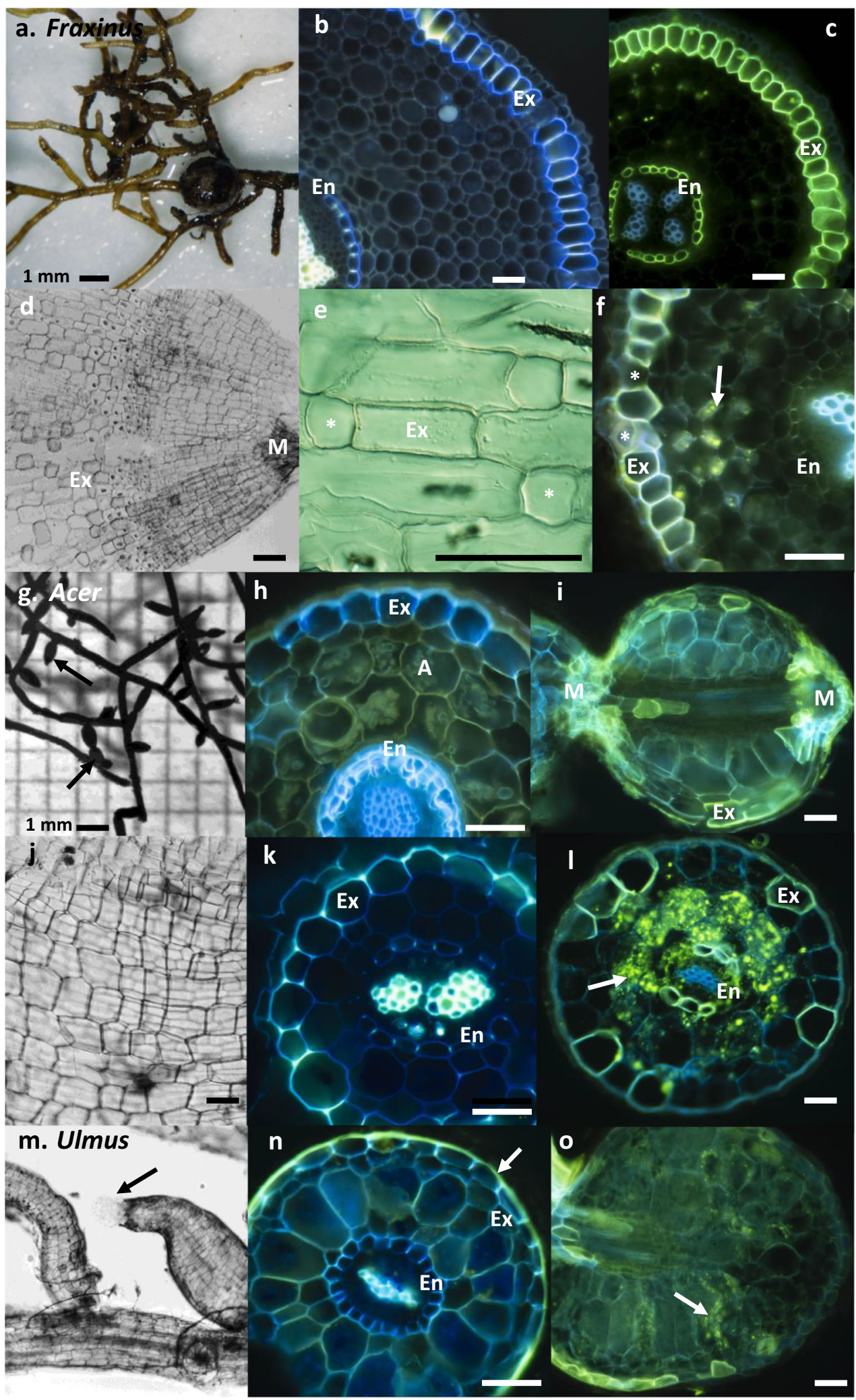




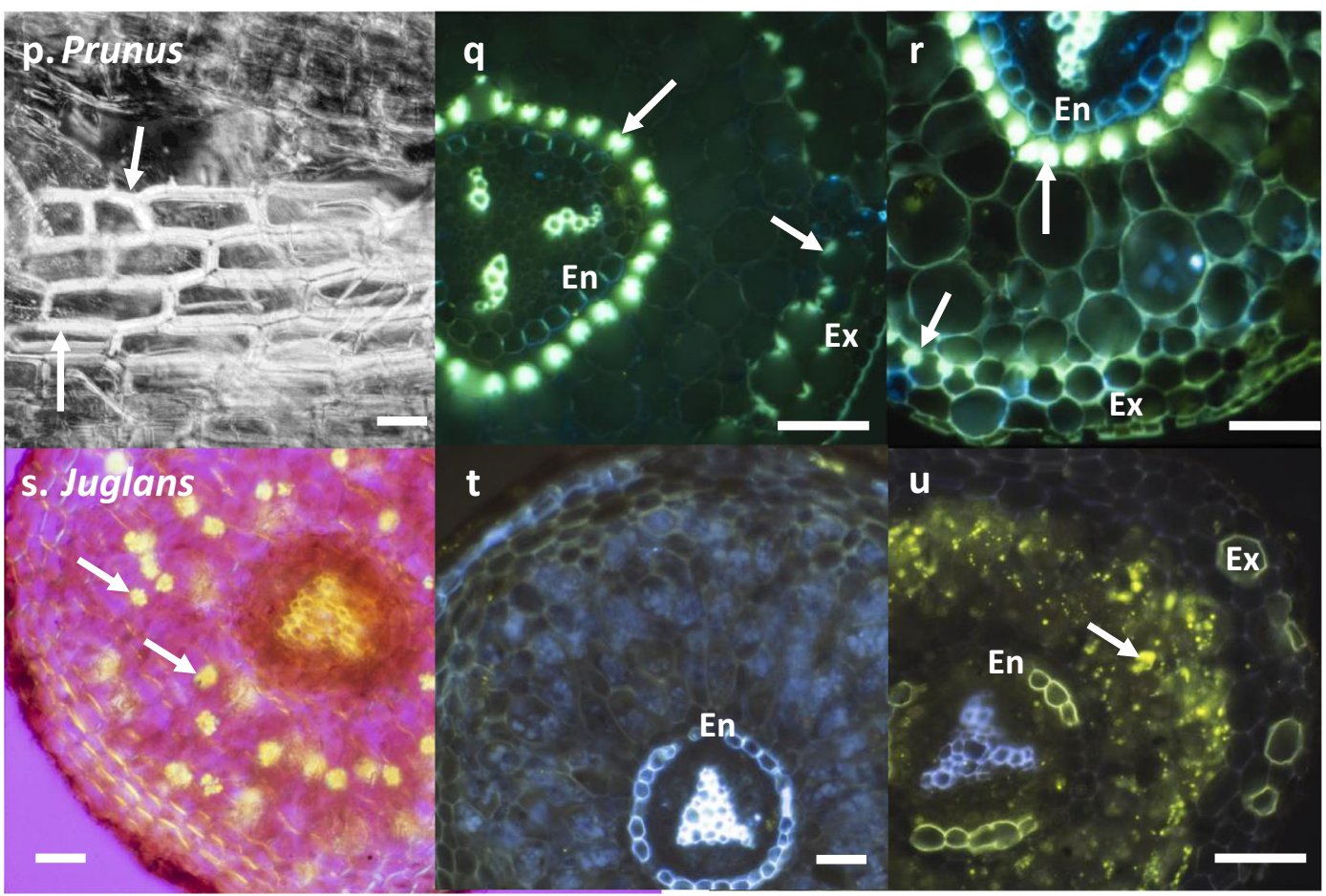

Fig. 7 (continued)

trees. There are 4 records of AM in Platanus and one report of EcM we consider to be incorrect (Fig. 12a). Substantial growth responses to AM inoculation occur in Platanus (Tisserant et al. 1990).

\section{Characteristic anatomical features of mycorrhizal roots}

As illustrated in Figs. 1 to 7 and summarised in Table 1, the root systems of EcM plants tend to vary considerably from those forming $\mathrm{AM}$ as a result of evolutionary pressure to become more efficient at forming mycorrhizas (Brundrett 2002). A common trend in EcM roots is for early periderm formation and cortex shedding in long roots resulting in loss of potential habitat for AMF (Lyr and Hofmann 1967; Brundrett et al. 1990). In the case of AM roots, it is common for the Casparian bands and suberin lamellae of exodermal cells to form substantial permeability barriers between fungi on the root surface and plant cells inside the root (Enstone et al. 2002;
Fig. 8 Database records for the 12 most commonly sampled genera of gymnosperm trees (conifers) native to the Northern Hemisphere (1188 records for 229 species) from the FungalRoot database (Soudzilovskaia et al. 2020)

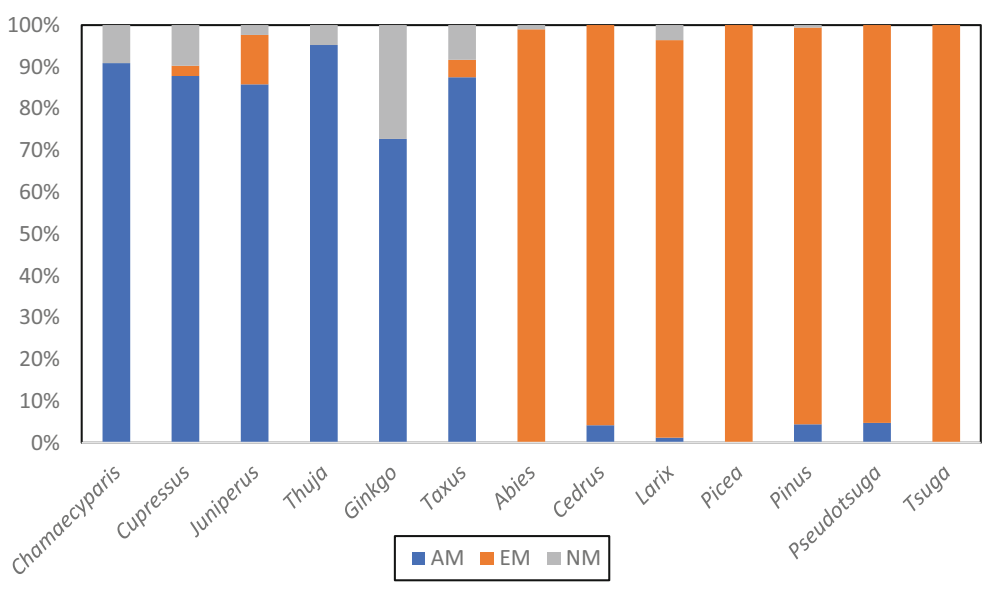




\section{a}

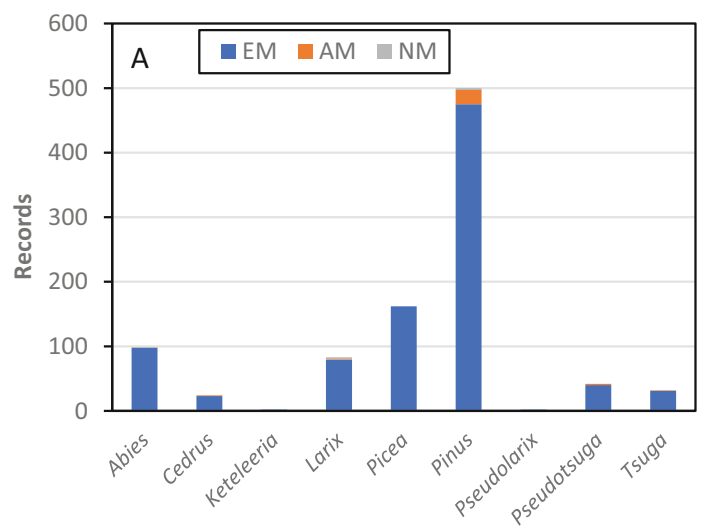

Fig. 9 Summary of mycorrhizal data for EM genera in the Pinaceae from the FungalRoot database (946 records for 155 species). a. Number of samples and reported mycorrhizal status

Brundrett 2002). Species of Acer, Fraxinus and Ulmus provide the most extreme examples due to very highly suberized outer exodermal cell walls (Table 1). In contrast the exodermis of many angiosperm EcM roots was incompletely suberised or absent below the Hartig net, presumably to allow more efficient exchange processes with adjacent epidermal cells (Table 1). Many AM plants such as Fraxinus species have a dimorphic exodermis (Fig. 7b-f) which is considered to be a protective barrier to solute loss and an important defence structure b

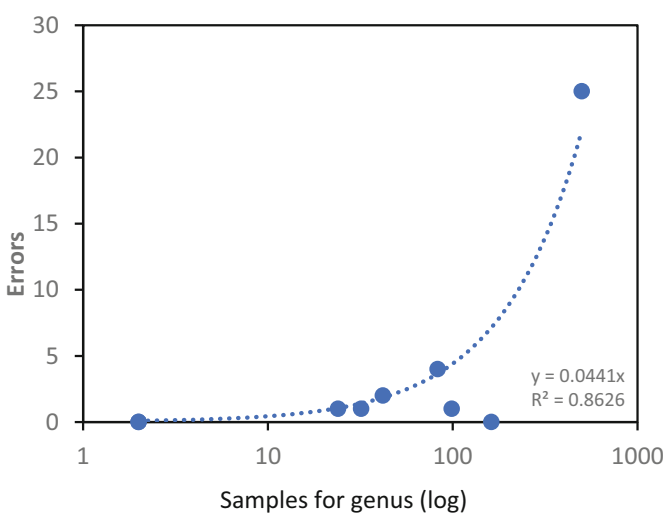

for all sampled genera. b. Published mycorrhizal diagnosis errors (AM, NM or AM-EM) plotted against the total number or records for each genus

against fungal invasion (Shishkoff 1987; Brundrett and Kendrick 1988; Enstone et al. 2002). This consists of alternating long and short cells (see Fig. 7bf), and the latter are the only places were AM fungi can enter roots (Sharda and Koide 2008). It seems likely that the structure of exodermal and epidermal cell walls in many AM plants is incompatible with EcM formation, but this requires further investigation.

As explained above, some AM trees (Acer, Ulmus, Rosaceae, etc.) have beaded roots which have misled

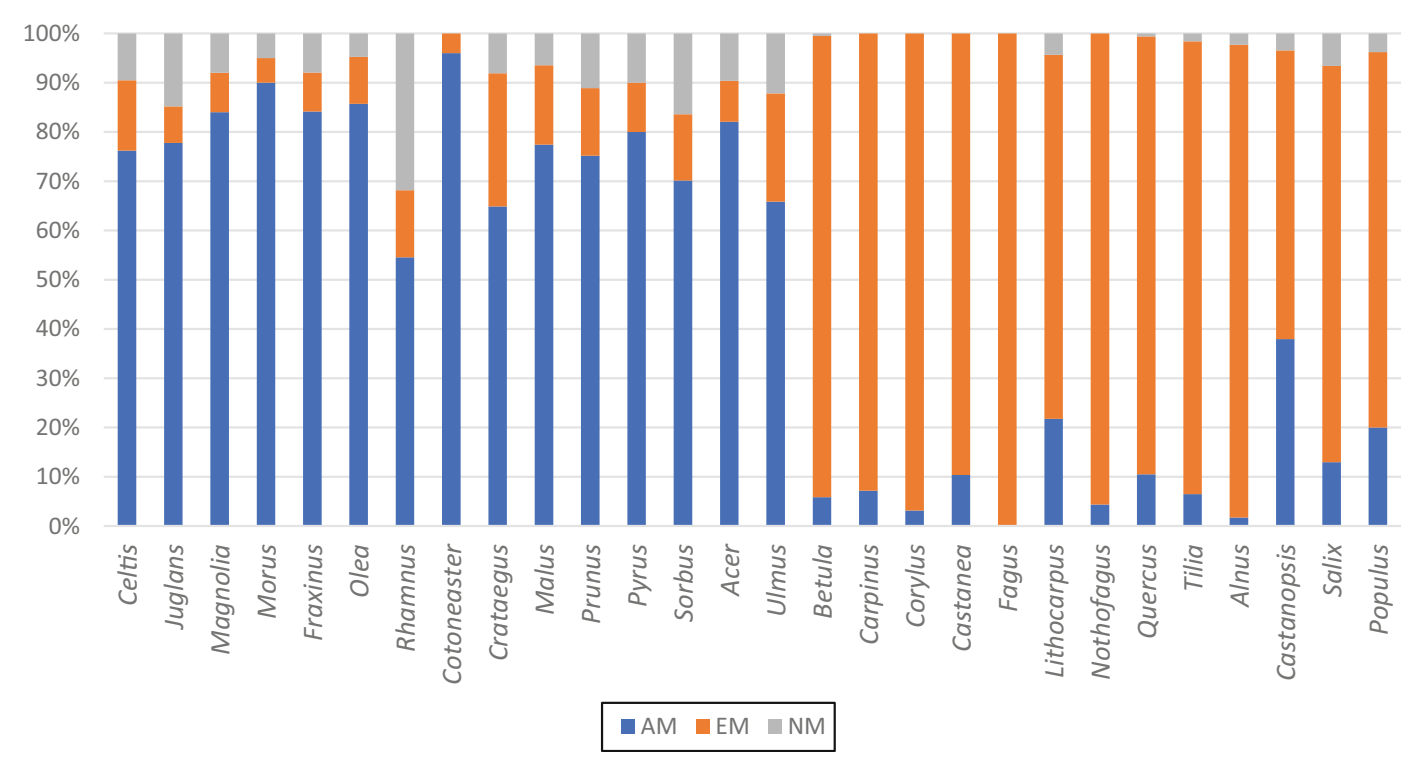

Fig. 10 Database records for the 29 most commonly sampled Angiosperm tree genera native to the Northern Hemisphere (2309 records for 557 species) from the FungalRoot database (Soudzilovskaia et al. 2020) 
Fig. 11 The relationship between samples and errors in mycorrhizal diagnosis for individual species of Northern Hemisphere trees in the Rosaceae included in the FungalRoot database (Soudzilovskaia et al. 2020). The regression is for all samples combined and many points overlap

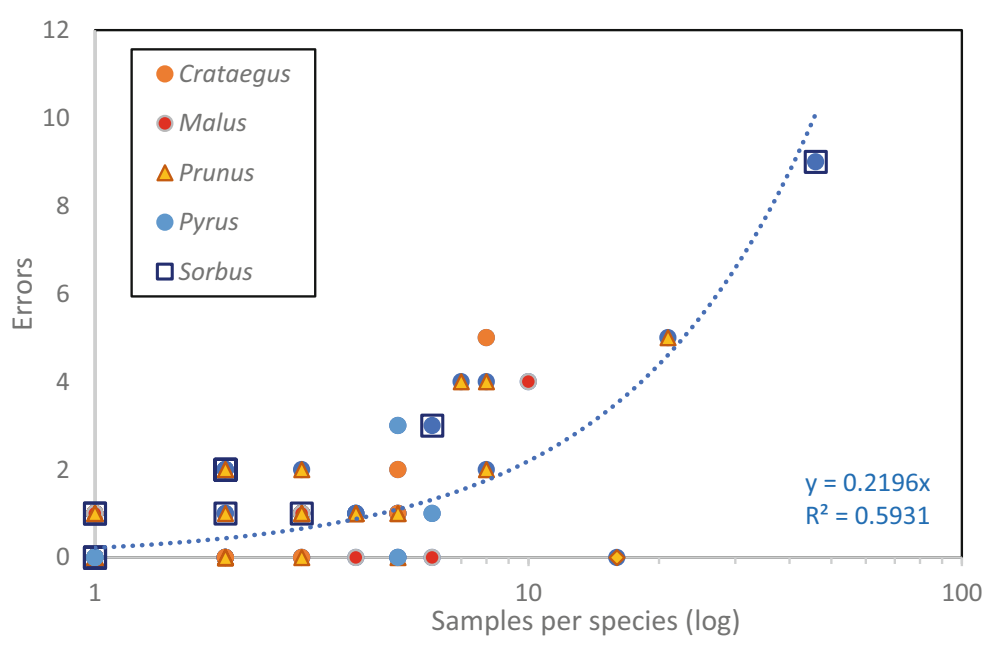

some observers into thinking they are EcM because these constrictions resemble short roots in the absence of careful microscopic examination (Fig. 7h-o). Beaded roots are caused when metacutinisation (suberized root caps) of dormant roots is followed by resumed growth where the apex breaks through these constrictions (Kessler 1966; Brundrett et al. 1990). This type of modular AM formation is considered to be an adaption to regulate the energy costs of association more effectively (Brundrett et al. 1990). Another key feature of most AM roots is a multilayered cortex, which primarily serves as a habitat for AM fungi and is protected by a highly suberised exodermis (Table 1).

Detailed studies of mycorrhizal root anatomy in this and earlier studies have revealed an evolutionary sequence in EcM roots that has resulted in convergence in root form (Brundrett et al. 1990). Common features in "advanced" EcM roots include highly branched short lateral roots, reduction in the number of cortical cell layers and substantial strengthening of inner cortex cell walls (Table 1). Permeability barriers under the Hartig net that may help to control plant-fungus exchange processes also occur in some cases. The thickened walls of inner-cortex cells under the Hartig net may be a response to osmotic stress (Brundrett et al. 1990). Similar features occur in the inner cortex of some gymnosperm trees (Larix, Abies and Tsuga species), but to a lesser extent (Fig. 3). It has been suggested that these thickened cell walls limit inward growth by EcM fungi in gymnosperm associations (Nylund 1987; MacKenzie 1983). Despite the more recent origin of angiosperm EcM associations (Tedersoo and Brundrett 2017), their degree of root anatomical specializations for efficient mycorrhizal formation are more extreme than in the Pinaceae (Figs. 2 and 3).

Plants with EcM typically also have dimorphic (heterorhizic) root systems where convergent evolution produces distinct long and short roots, but only the latter house EcM (KubÍková 1967; Brundrett et al. 1990; Peterson et al. 2004). Short roots have limited apical growth and much more frequent branching. They also show clear signs of synchronised development of epidermal cells with fungal hyphae to increase interface surface area in angiosperm EcM roots. Another common feature of both angiosperms and gymnosperms with EcM is early secondary growth in long roots, which results in the loss of habitat for AM fungi in the primary cortex over a large proportion of the root system. Salix roots differ from the other EcM trees illustrated here because they have longer short roots with limited branching and thinner Hartig nets (Fig. 4g). These trees have EcM, with some AM and can occur in waterlogged or disturbed soils, which may also impact on the intensity of EcM formation (Tedersoo and Brundrett 2017).

As shown in Table 1, roots typically have specialised anatomical features that are specific to one type of mycorrhizal association (Brundrett et al. 1990; Brundrett 2002; Sharda and Koide 2008). The primary functions of these seem to be to (i) control the activity of mycorrhizal fungi, (ii) prevent the loss of nutrients from the mycorrhizal interface area and (iii) keep harmful or incompatible fungi, including those causing other types or mycorrhizas, from entering roots. 

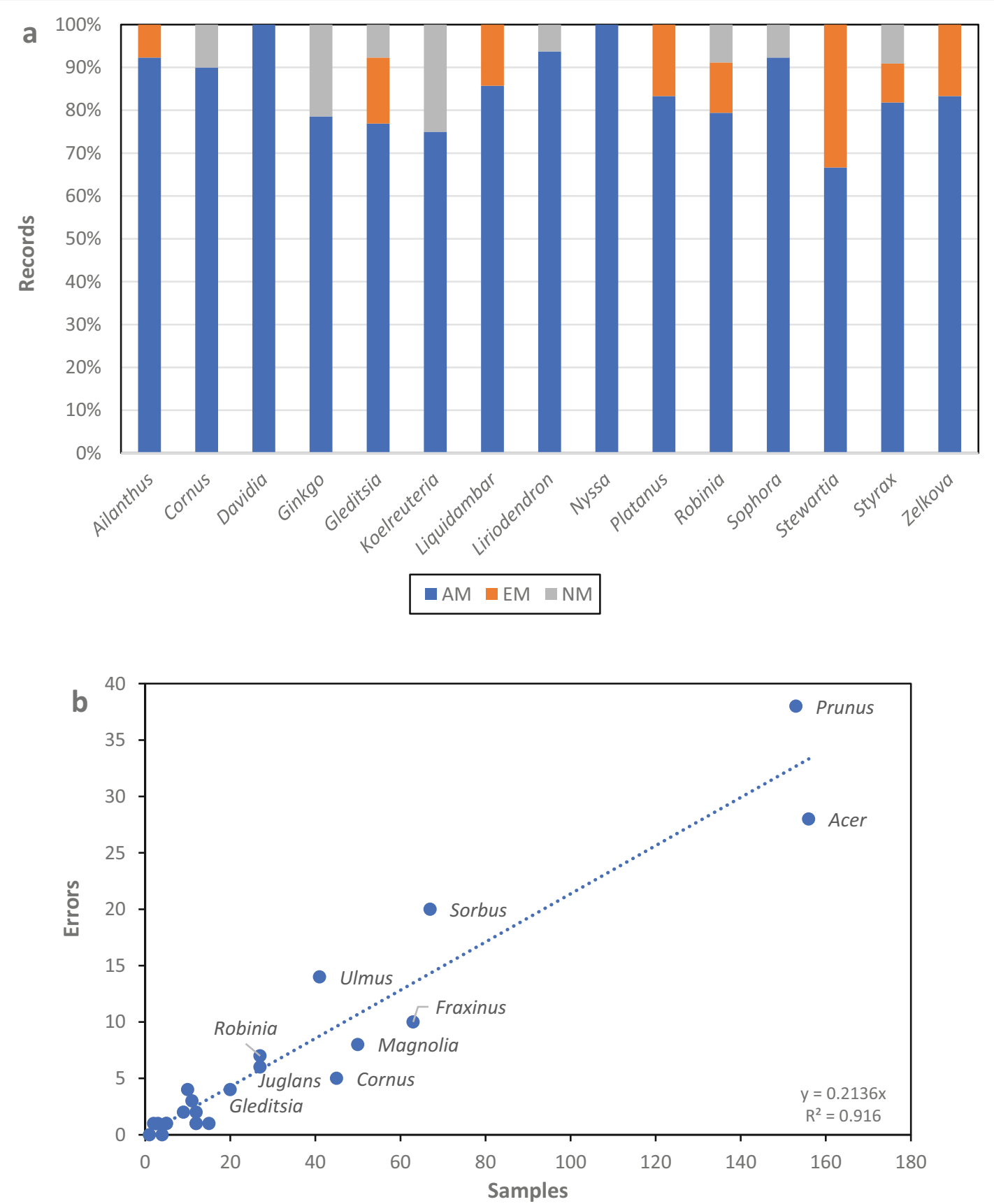

Fig. 12 a. Mycorrhizal status records from 23 genera of commonly planted AM street trees from the FungalRoot database (Soudzilovskaia et al. 2020), excluding genera in Fig. 10 (Acer, Fraxinus, Juglans, Magnolia, Prunus, Pyrus, Sorbus and Malus).

Roots are more structurally complex than is often acknowledged and many of their specialised anatomical features help to regulate mycorrhizal associations (Brundrett 2002; Table 1). Some of these anatomical specialisations are likely to restrict the ability of plants b. There is a very high correlation between numbers of records and cases of mycorrhizal misdiagnosis for these trees (the 10 most commonly studied genera are labelled)

to adopt to new types of mycorrhizas, since they would initially be inefficient at or unable to form novel associations. Despite this limitation, a number of clades of trees have successfully switched from AM to EcM, but few if any have switched from EcM to AM, or from AM to NM 
Fig. 13 Mycorrhizal tree biomass calculated for Eurasia and North America divided by vegetation type (a) or tree type (b). Data are from Soudzilovskaia et al. (2019) for vegetation classes dominated by trees following the ESA global landcover product map for 2015 (www.esalandcover-cci.org). Values are biomass estimates in gigatons (GT)

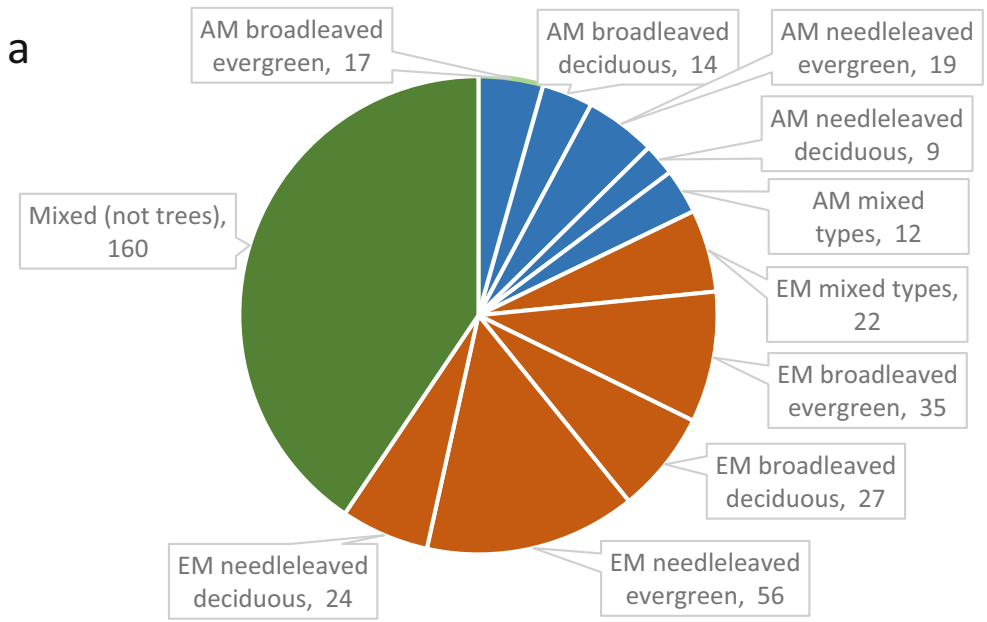

b

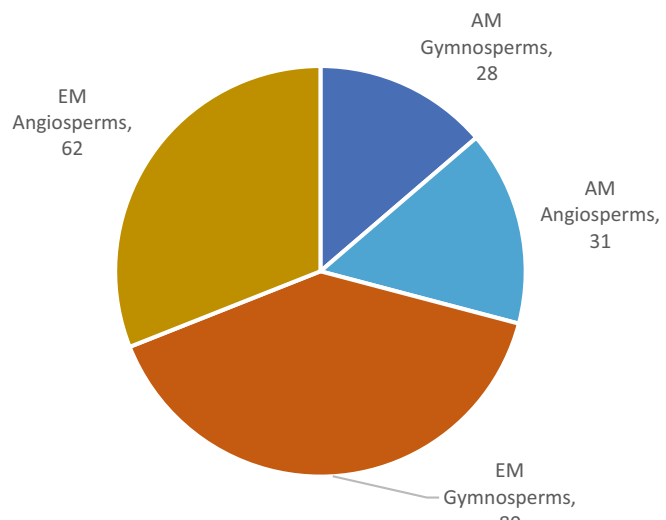

80

roots (some examples occur outside of temperate northern biomes). Overall, there are about 30 lineages where switching from AM to EcM has occurred (Tedersoo and Brundrett 2017). There also are several cases of NM to EcM switching in herbaceous plants. However, the overwhelming majority of lineages of plants that often grow in the presence of EcM fungi do not switch their root traits. These evolutionary trends suggest that there must be minor advantages to casual contact between AM roots and EcM fungi to both organisms in some
Fig. 14 Comparing mycorrhizal data consistency for 205 species of trees with complex root anatomy (CRA) with all other tree species in this study (735). CRA trees have beaded roots or prominent phi thickenings of cortex cells that are linked to diagnosis errors (see text). Standard error bars are shown

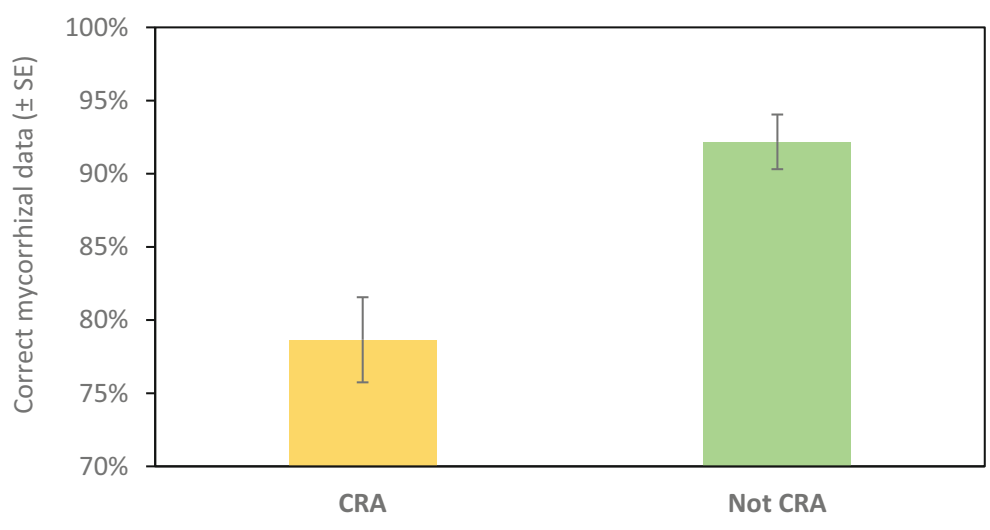


circumstances. These proto-EcM associations should not be treated as EcM if they lack a Hartig net and occur in roots where AM fungi would be responsible for most nutrient uptake. There are more recent examples of recent AM to EcM transitions in Australia than elsewhere, especially in regions with extremely infertile soils and semiarid climates and these are likely to be the be key driver driving forces in these evolutionary trends (Brundrett 2017). Due to the complexity of changes required for roots to transition from efficient $\mathrm{AM}$ to efficient EM associations, this must be a gradual process, but more research is required to investigate how this happens and why it happens so infrequently.

The trees included in Table 1 belong to eight separate clades, of which four are predominantly or fully EcM. These diverged from their AM ancestors in the Cretaceous era or before (110-190 Ma) for the Pinaceae and the Fagales (84-105 Ma), or the Paleogene era (30$50 \mathrm{Ma}$ ) for the others (Tedersoo and Brundrett 2017). The genera Alnus and Corylus originated at about 45 and 35 Ma respectively (Larson-Johnson 2016) and have regained some capacity for AM (EcM-AM roots). The family Salicaceae also includes EcM-AM species, but is substantially older, at about $80 \mathrm{Ma}$ (Xi et al. 2012). There also is one transition from EcM to fully AM roots in the Fagales for Juglans species in the Juglandaceae a family which also includes EcM genera such as Carya. The origin of Juglans occurred at about $45 \mathrm{Ma}$ (Larson-Johnson 2016). There is no concrete evidence of more recent transitions between AM and $\mathrm{EcM}$ in the clades of trees considered here.

\section{Conclusions and recommendations}

This paper demonstrates how consolidating mycorrhizal records in a new database (FungalRoot) has allowed us to identify contradictions in the mycorrhizal literature and resolve them for the most important northern hemisphere trees. In all cases, our expert diagnosis agrees with the majority of data and we can often explain how incorrect information originated (we consider only $10 \%$ of data to be incorrect overall for trees). However, trees have been the subject of numerous studies, so have accumulated more mycorrhizal status errors in uncorrected databases than other plants. Consequently, there are many cases where metastudies have included incorrect mycorrhizal trait data for them (Brundrett and Tedersoo 2019).
Not all errors in mycorrhizal trait data are random, since there are a greater number of incorrect datapoints for trees in families with complex root anatomy. Nevertheless, there is a very strong overall linear relationship overall between sample numbers and errors for species, which are usually not correlated with plant systematics or growing conditions. Our study has revealed the following key conclusions about mycorrhizal data quality for trees:

1. Most reports of AM in EcM trees can be discounted because arbuscules were not used to define associations.

2. There is a substantial number of reports of EcM in AM trees caused primarily by failure to use the Hartig net to define these mycorrhizas.

3. In the families Rosaceae, Ginkgoaceae, Taxaceae, and Cupressaceae, as well as the genera Acer and Ulmus, incorrect diagnosis of EcM is linked to anatomical features (beaded roots or phi thickenings) that have confused some observers.

4. Simple root misidentification also seems to be common in mixed forests, especially for AM trees such as Juniperus spp. that often co-occur with EcM conifers.

5. Mycorrhizal fungi frequently occur as endophytes in non-host plants so their detection by DNA-based methods or microscopy alone cannot be used to diagnose mycorrhizas.

6. Databases of mycorrhizal records accumulate errors unless there are rigorous approaches to maintain data quality.

7. Data from older sources must be interpreted very carefully, because standardized definitions of mycorrhizal types and efficient methods for examining roots were not yet in use.

Protocols for correct identification of mycorrhizal associations are presented elsewhere (Brundrett 2009; Brundrett and Tedersoo 2019). All mycorrhizal scientists require sufficient training to identify mycorrhizal associations using rigorous diagnostic criteria (see Brundrett 2009), but they also need to understand anatomical features of roots that regulate mycorrhiza formation. We recommend that future metastudies use corrected databases and any remaining contradictory data be resolved by evaluating new root samples using appropriate methodology and definitions of association types.

It is very important to understand the correct mycorrhizal status of trees. This knowledge is required to help horticulturists and foresters grow trees in the nursery 
and prevent the use of inappropriate microbial inoculants. Foresters, botanists and ecologists also require reliable data on the importance of trees with EcM or $\mathrm{AM}$, to allow local, regional and global analyses of mycorrhizal roles in ecosystems, now and in the past (e.g. Chen et al. 2016; Valverde-Barrantes et al. 2017; Pither et al. 2018; Soudzilovskaia et al. 2019; Steidinger et al. 2019; Li et al. 2020; Tedersoo et al. 2020). Overall $\mathrm{EcM}$ trees are more dominant in northern temperate forest than in most other regions globally (Fig. 13). The relative dominance of trees with different mycorrhizal association types is linked to variations in nutrient cycling processes and other ecological processes as discussed in greater detail elsewhere (see Li et al. 2020; Tedersoo et al. 2020).

As explained above, convergent evolution results in different clades with the same type of mycorrhizas having similar anatomical features in roots with AM or EcM. Presumably active defence mechanisms and avoidance responses by fungi also help to explain why the majority of Northern Hemisphere trees only successfully form one type of mycorrhizas. Further research is required to fully understand how root structures along with interacting physiological and genetic processes in plants and fungi regulate mycorrhizal formation and specificity. There is also great scope to investigate the nature of interactions between mycorrhizal fungi and the roots of non-host plants, which may include endophytic activity (Murata et al. 2014) and possible intermediates between mycorrhizal and nonmycorrhizal states (Thoen et al. 2020). Despite the complexity of root-fungus interactions and occasional diagnosis errors, the majority of trees species investigated here can be shown to have highly consistent mycorrhizal associations of a single type. There is also sufficient physiological data to support the concept that these associations are of fundamental importance to their growth and the sustainability of ecosystems where they occur.

Acknowledgements We are grateful to Nadia Soudzilovskaia and other authors of the global mycorrhizal tree maps for providing estimates for mycorrhizal tree biomass and for constructive comments on the manuscript. This project did not receive specific funding.

\section{Appendix}

Table 2 List of trees included in this study with their designated mycorrhizal status and the proportion of data that agrees with this diagnosis (data correct). Data are from the FungalRoot database (Soudzilovskaia et al. 2020)

\begin{tabular}{|c|c|c|c|c|c|c|}
\hline Family & Genus & Mycorrhiza & Species sampled & Total samples & Data correct & Notes \\
\hline \multicolumn{7}{|l|}{ Gymnosperms } \\
\hline Cupressaceae & Chamaecyparis & $\mathrm{AM}$ & 5 & 22 & $91 \%$ & \\
\hline Cupressaceae & Cupressus & $\mathrm{AM}$ & 10 & 41 & $88 \%$ & \\
\hline Cupressaceae & Juniperus & $\mathrm{AM}$ & 33 & 127 & $86 \%$ & CRA \\
\hline Cupressaceae & Thuja & $\mathrm{AM}$ & 3 & 21 & $95 \%$ & CRA \\
\hline Ginkgoaceae & Ginkgo & $\mathrm{AM}$ & 1 & 11 & $73 \%$ & CRA \\
\hline Pinaceae & Abies & EM & 32 & 99 & $99 \%$ & \\
\hline Pinaceae & Cedrus & EM & 3 & 24 & $96 \%$ & \\
\hline Pinaceae & Larix & EM & 16 & 83 & $95 \%$ & \\
\hline Pinaceae & Picea & EM & 25 & 162 & $100 \%$ & \\
\hline Pinaceae & Pinus & EM & 85 & 500 & $95 \%$ & \\
\hline Pinaceae & Pseudotsuga & EM & 6 & 42 & $95 \%$ & \\
\hline Pinaceae & Tsuga & EM & 6 & 32 & $100 \%$ & \\
\hline Taxaceae & Taxus & $\mathrm{AM}$ & 4 & 24 & $88 \%$ & \\
\hline
\end{tabular}


Table 2 (continued)

\begin{tabular}{|c|c|c|c|c|c|c|}
\hline Family & Genus & Mycorrhiza & Species sampled & Total samples & Data correct & Notes \\
\hline Altingiaceae & Liquidambar & $\mathrm{AM}$ & 3 & 12 & $83 \%$ & \\
\hline Anacardiaceae & Pistacia & $\mathrm{AM}$ & 6 & 13 & $85 \%$ & \\
\hline Anacardiaceae & Rhus & $\mathrm{AM}$ & 10 & 16 & $81 \%$ & \\
\hline Aquifoliaceae & Ilex & $\mathrm{AM}$ & 22 & 35 & $89 \%$ & \\
\hline Betulaceae & Alnus & EM-AM & 32 & 174 & $96 \%$ & \\
\hline Betulaceae & Betula & EM & 30 & 205 & $94 \%$ & \\
\hline Betulaceae & Carpinus & EM & 6 & 28 & $93 \%$ & \\
\hline Betulaceae & Corylus & EM (AM) & 5 & 64 & $97 \%$ & \\
\hline Cannabaceae & Celtis & $\mathrm{AM}$ & 12 & 21 & $76 \%$ & \\
\hline Cornaceae & Cornus & $\mathrm{AM}$ & 15 & 45 & $89 \%$ & \\
\hline Elaeocarpaceae & Elaeocarpus & $\mathrm{AM}$ & 15 & 19 & $79 \%$ & \\
\hline Ericaceae & Arbutus & $\mathrm{EM}$ & 2 & 19 & $95 \%$ & \\
\hline Ericaceae & Gaultheria & Ericoid & 16 & 29 & $72 \%$ & \\
\hline Ericaceae & Rhododendron & Ericoid & 36 & 60 & $52 \%$ & \\
\hline Fabaceae & Gleditsia & $\mathrm{AM}$ & 5 & 10 & $60 \%$ & \\
\hline Fabaceae & Robinia & $\mathrm{AM}$ & 2 & 27 & $74 \%$ & \\
\hline Fabaceae & Sophora & $\mathrm{AM}$ & 7 & 12 & $92 \%$ & \\
\hline Fagaceae & Castanea & EM & 6 & 29 & $90 \%$ & \\
\hline Fagaceae & Castanopsis & EM & 15 & 29 & $59 \%$ & \\
\hline Fagaceae & Fagus & EM & 8 & 125 & $100 \%$ & \\
\hline Fagaceae & Lithocarpus & EM & 13 & 23 & $74 \%$ & \\
\hline Fagaceae & Quercus & $\mathrm{EM}$ & 53 & 162 & $89 \%$ & \\
\hline Juglandaceae & Juglans & $\mathrm{AM}$ & 6 & 27 & $78 \%$ & \\
\hline Magnoliaceae & Liriodendron & $\mathrm{AM}$ & 2 & 15 & $93 \%$ & \\
\hline Magnoliaceae & Magnolia & $\mathrm{AM}$ & 30 & 50 & $84 \%$ & \\
\hline Malvaceae & Tilia & EM & 11 & 62 & $92 \%$ & \\
\hline Moraceae & Morus & $\mathrm{AM}$ & 3 & 20 & $90 \%$ & \\
\hline Myricaceae & Myrica & $\mathrm{AM}$ & 8 & 23 & $57 \%$ & \\
\hline Oleaceae & Fraxinus & $\mathrm{AM}$ & 15 & 63 & $84 \%$ & \\
\hline Oleaceae & Ligustrum & $\mathrm{AM}$ & 6 & 19 & $84 \%$ & \\
\hline Oleaceae & Olea & $\mathrm{AM}$ & 7 & 21 & $86 \%$ & \\
\hline Platanaceae & Platanus & $\mathrm{AM}$ & 3 & 5 & $80 \%$ & \\
\hline Rhamnaceae & Rhamnus & $\mathrm{AM}$ & 10 & 22 & $100 \%$ & \\
\hline Rosaceae & Cotoneaster & $\mathrm{AM}$ & 13 & 25 & $96 \%$ & CRA \\
\hline Rosaceae & Crataegus & $\mathrm{AM}$ & 16 & 37 & $65 \%$ & CRA \\
\hline Rosaceae & Malus & $\mathrm{AM}$ & 12 & 31 & $77 \%$ & CRA \\
\hline Rosaceae & Prunus & $\mathrm{AM}$ & 53 & 153 & $75 \%$ & CRA \\
\hline Rosaceae & Pyrus & $\mathrm{AM}$ & 8 & 20 & $80 \%$ & CRA \\
\hline Rosaceae & Sorbus & $\mathrm{AM}$ & 13 & 67 & $70 \%$ & CRA \\
\hline Salicaceae & Populus & $\mathrm{EM}(\mathrm{AM})$ & 28 & 185 & $96 \%$ & \\
\hline Salicaceae & Salix & EM-AM (NM) & 86 & 394 & $97 \%$ & cold, wet \\
\hline Sapindaceae & Acer & $\mathrm{AM}$ & 37 & 156 & $82 \%$ & CRA \\
\hline Sapindaceae & Aesculus & $\mathrm{AM}$ & 3 & 9 & $78 \%$ & CRA \\
\hline Simaroubaceae & Ailanthus & $\mathrm{AM}$ & 3 & 12 & $92 \%$ & \\
\hline
\end{tabular}


Table 2 (continued)

\begin{tabular}{lllcrlr}
\hline Family & Genus & Mycorrhiza & Species sampled & Total samples & Data correct & Notes \\
\hline Styracaceae & Styrax & AM & 6 & 9 & $78 \%$ & CRA \\
Ulmaceae & Ulmus & AM & 11 & 41 & $56 \%$ & CRA \\
Ulmaceae & Zelkova & AM & 2 & 3816 & $90 \%$ & $90 \%$ \\
Total & & & 940 & & \\
\hline
\end{tabular}

$A M$, arbuscular mycorrhizas; $E M$, ectomycorrhizas; (NM), occasionally nonmycorrhizal; $C R A$, complex root anatomy; cold, occurs in arctic habitats; wet, occurs in very wet habitats

\section{References}

Ambriz E, Báez-Pérez A, Sánchez-Yáñez JM, Moutoglis P, Villegas J (2010) Fraxinus-Glomus-Pisolithus symbiosis: plant growth and soil aggregation effects. Pedobiologia 53: 369-373

Aristizábal C, Rivera EL, Janos DP (2004) Arbuscular mycorrhizal fungi colonize decomposing leaves of Myrica parvifolia. M pubescens and Paepalanthus sp Mycorrhiza 14:221-228

Bainard LD, Klironomos JN, Gordon AM (2011) The mycorrhizal status and colonization of 26 tree species growing in urban and rural environments. Mycorrhiza 21:91-96

Beauchamp VB, Stromberg JC, Stutz JC (2006) Arbuscular mycorrhizal fungi associated with Populus-Salix stands in a semiarid riparian ecosystem. New Phytol 170:369-380

Becerra AG, Nouhra ER, Silva MP, McKay D (2009) Ectomycorrhizae, arbuscular mycorrhizae, and dark-septate fungi on Salix humboldtiana in two riparian populations from Central Argentina. Mycoscience 50:343-352

Benucci GMN, Csorbai AG, Falini LB et al (2012) Mycorrhization of Quercus robur L., Quercus cerris L. and Corylus avellana L. seedlings with Tuber macrosporum Vittad. Mycorrhiza 22:639-646

Berta G, Trotta A, Fusconi A, Hooker JE, Munro M, Atkinson D, Giovannetti M, Morini S, Fortuna P, Tisserant B, GianinazziPearson V (1995) Arbuscular mycorrhizal induced changes to plant growth and root system morphology in Prunus cerasifera. Tree Physiol 15:281-293

Bonfante-Fasolo P, Fontana A (1985) VAM fungi in Ginkgo biloba roots: their interactions at cellular level. Symbiosis 1:53-67

Brundrett MC (2002) Coevolution of roots and mycorrhizas of land plants. New Phytol 154:275-304

Brundrett M (2004) Diversity and classification of mycorrhizal associations. Biol Rev 79:473-495

Brundrett MC (2009) Mycorrhizal associations and other means of nutrition of vascular plants: understanding the global diversity of host plants by resolving conflicting information and developing reliable means of diagnosis. Plant Soil 320:37-77

Brundrett MC. 2017. Global diversity and importance of mycorrhizal and nonmycorrhizal plants. In: Biogeography of Mycorrhizal Symbiosis. Springer, Cham, 533-556

Brundrett MC, Kendrick B (1987) The relationship between the ash bolete (Boletinellus merulioides) and an aphid parasitic on ash tree roots. Symbiosis 3:15-320
Brundrett MC, Kendrick B (1988) The mycorrhizal status, root anatomy, and phenology of plants in a sugar maple forest. Can J Bot 66:1153-1173

Brundrett MC, Tedersoo L (2018) Evolutionary history of mycorrhizal symbioses and global host plant diversity. New Phytol 220:1108-1115

Brundrett M, Tedersoo L (2019) Misdiagnosis of mycorrhizas and inappropriate recycling of data can lead to false conclusions. New Phytol 221:18-24

Brundrett MC, Enstone DE, Peterson CA (1988) A berberineaniline blue fluorescent staining procedure for suberin, lignin, and callose in plant tissue. Protoplasma 146:133-142

Brundrett M, Murase G, Kendrick B (1990) Comparative anatomy of roots and mycorrhizae of common Ontario trees. Can J Bot 68:551-578

Brundrett MC, Kendrick B, Peterson CA (1991) Efficient lipid staining in plant material with Sudan red 7B or Fluoral yellow 088 in polyethylene glycol-glycerol. Biotechnic \& Histochemistry 66:111-116

Brundrett M, Bougher N, Dell B, et al (1996) Working with Mycorrhizas in forestry and agriculture. Australian Centre for International Agricultural Research (ACIAR)

Bueno CG, Gerz M, Zobel M, Moora M (2019) Conceptual differences lead to divergent trait estimates in empirical and taxonomic approaches to plant mycorrhizal trait assignment. Mycorrhiza 29:1-11

Cázares E, Trappe JM (1993) Vesicular endophytes in roots of the Pinaceae. Mycorrhiza 2:153-156

Chen W, Koide RT, Adams TS, DeForest JL, Cheng L, Eissenstat DM (2016) Root morphology and mycorrhizal symbioses together shape nutrient foraging strategies of temperate trees. Proc Natl Acad Sci 113:8741-8746

Chenchouni H, Mekahlia MN, Beddiar A (2019) Effect of inoculation with native and commercial arbuscular mycorrhizal fungi on growth and mycorrhizal colonization of olive (Olea europaea L.). Scientia Horticulturae 19:108969

Cosme M, Fernández I, Van der Heijden MG, Pieterse CM (2018) Non-mycorrhizal plants: the exceptions that prove the rule. Trends Plant Sci 23:577-587

Delaux P-M, Varala K, Edger PP, Coruzzi GM, Pires JC, Ané J-M (2014) Comparative phylogenomics uncovers the impact of symbiotic associations on host genome evolution. PLoS Genet 10:e1004487

Demars BG, Boerner RE (1996) Vesicular arbuscular mycorrhizal development in the Brassicaceae in relation to plant life span. Flora 191:179-189 
Dickie IA, Holdaway RJ (2011) Podocarp roots, mycorrhizas, and nodules. Smithson Contrib Bot 95:175-187

Dickie IA, Bolstridge N, Cooper JA, Peltzer DA (2010) Coinvasion by Pinus and its mycorrhizal fungi. New Phytol 187:475-484

Dickie IA, Bufford JL, Cobb RC, Desprez-Loustau ML, Grelet G, Hulme PE, Klironomos J, Makiola A, Nuñez MA, Pringle A, Thrall PH, Tourtellot SG, Waller L, Williams NM (2017) The emerging science of linked plant-fungal invasions. New Phytol 215:1314-1332

Enstone DE, Peterson CA, Ma F (2002) Root endodermis and exodermis: structure, function, and responses to the environment. J Plant Growth Regul 21:335-351

Facelli E, Smith SE, Facelli JM, Christophersen HM, Andrew SF (2010) Underground friends or enemies: model plants help to unravel direct and indirect effects of arbuscular mycorrhizal fungi on plant competition. New Phytol 185:1050-1061

Fehrer J, Réblová M, Bambasová V, Vohník M (2019) The rootsymbiotic Rhizoscyphus ericae aggregate and Hyaloscypha (Leotiomycetes) are congeneric: phylogenetic and experimental evidence. Stud Mycol 92:195-225

Fontana A (1985) Vesicular-arbuscular mycorrhizas of Ginkgo biloba 1 . in natural and controlled conditions. New Phytol 99:441-447

Fortas Z, Chevalier G (1992) Effet les conditions de culture sur la mycorhization de l'Helianthemum guttatum par trois espéces de terfez des genres Terfezia et Tirmania d'Algerie. Can J Bot 70:2453-2460

Frank B (1885) Über die auf Wurzelsymbiose beruhende Ernährung gewisser Bäume durch unterirdische Pilze. Berichte der Deutschen Botanischen Gessellschaft 3:128-145

Gallaud I. 1905. Etudes sur les mycorrhizes endophytes. Revue General de Botanique 17: 5-48, 66-83, 123-136, 223-239, 313-325, 425-433, 479-500

Gehring CA, Mueller RC, Whitham TG (2006) Environmental and genetic effects on the formation of ectomycorrhizal and arbuscular mycorrhizal associations in cottonwoods. Oecologia 149:158-164

Gerrath JM, Covington L, Doubt J, Larson DW (2002) Occurrence of phi thickenings is correlated with gymnosperm systematics. Can J Bot 80:852-860

Giovannetti M, Sbrana C (1998) Meeting a non-host: the behaviour of AM fungi. Mycorrhiza 8:123-130

Giovannetti M, Sbrana C, Logi C (1994) Early processes involved in host recognition by arbuscular mycorrhizal fungi. New Phytol 127:703-709

Greene DW, Manning WJ, Cooley DR (1982) Effect of the ectomycorrhizal fungus Pisolithus tinctorius and auxin rooting formulations on growth of 'Cortland' apple trees [Malus domestica, nutrient uptake]. HortScience

Grove S, Haubensak KA, Gehring C, Parker IM (2017) Mycorrhizae, invasions, and the temporal dynamics of mutualism disruption. J Ecol 105:1496-1508

Hacquard S, Tisserant E, Brun A, Legué V, Martin F, Kohler A (2013) Laser microdissection and microarray analysis of Tuber melanosporum ectomycorrhizas reveal functional heterogeneity between mantle and Hartig net compartments. Environ Microbiol 15:1853-1869

Harley JL, Harley EL. 1987. A check-list of mycorrhiza in the British flora. New Phytologist 105 (suppliment): 1-102
Hoeksema J, Roy M, Laska G et al (2018) Pulsatilla patens (Ranunculaceae), a perennial herb, is ectomycorrhizal in northeastern Poland and likely shares ectomycorrhizal fungi with Pinus sylvestris. Acta Soc Bot Pol 87

Horton TR, Cázares E, Bruns TD (1998) Ectomycorrhizal, vesicular-arbuscular and dark septate fungal colonization of bishop pine (Pinus muricata) seedlings in the first 5 months of growth after wildfire. Mycorrhiza 8:11-18

Jones MD, Smith SE (2004) Exploring functional definitions of mycorrhizas: are mycorrhizas always mutualisms? Can J Bot 82:1089-1109

Kariman K, Barker SJ, Jost R, Finnegan PM, Tibbett M (2014) A novel plant-fungus symbiosis benefits the host without forming mycorrhizal structures. New Phytol 201:1413-1422

Kelley AP (1950) Mycotrophy in plants. Lectures on the biology of mycorrhizae and related structures. Waltham, Mass., USA

Kessler KJ (1966) Growth and development of mycorrhizae of sugar maple (Acer saccharum marsh.). Can J Bot 44: 1413-1425

Khan AG (1972) Podocarp-type mycorrhizal nodules in Aesculus indica. Ann Bot 36:229-238

Khasa PD, Chakravarty P, Robertson A, Thomas BR, Dancik BP (2002) The mycorrhizal status of selected poplar clones introduced in Alberta. Biomass Bioenergy 22:99-104

Kilpeläinen J, Vestberg M, Repo T, Lehto T (2016) Arbuscular and ectomycorrhizal root colonisation and plant nutrition in soils exposed to freezing temperatures. Soil Biol Biochem 99:85-93

Kinden DA, Brown MF (1975) Electron microscopy of vesiculararbuscular mycorrhizae of yellow poplar. III Host-endophyte interactions during arbuscular development. Canadian Journal of Microbiology 21:1930-1939

Kohler A, Kuo A, Nagy LG, Morin E, Barry KW, Buscot F, Canbäck B, Choi C, Cichocki N, Clum A, Colpaert J (2015) Convergent losses of decay mechanisms and rapid turnover of symbiosis genes in mycorrhizal mutualists. Nat Genet 47(4):410-415

Kohout P. 2017. Biogeography of ericoid mycorrhiza. In: Biogeography of Mycorrhizal Symbiosis. Springer, 179-193

Koide RT, Mosse B (2004) A history of research on arbuscular mycorrhiza. Mycorrhiza 14:145-163

Kough JL, Molina R, Linderman RG (1985) Mycorrhizal responsiveness of Thuja, Calocedrus, Sequoia, and Sequoiadendron species of western North America. Can J For Res 15:1049-1054

Kovács GM, Vágvölgyi C, Oberwinkler F (2003) In vitro interaction of the truffle Terfezia terfezioides with Robinia pseudoacacia and Helianthemum ovatum. Folia Microbiol 248:369-378

Kubĺková J (1967) Contribution to the classification of root systems of woody plants. Preslia 39:236-243

Larson-Johnson K (2016) Phylogenetic investigation of the complex evolutionary history of dispersal mode and diversification rates across living and fossil Fagales. New Phytol 209: 418-435

Li J, Shangguan Z, Deng L (2020) Variations of belowground C and $\mathrm{N}$ cycling between arbuscular mycorrhizal and ectomycorrhizal forests across China. Soil Research. https://doi.org/10.1071/SR19377 
Lodge DJ (1989) The influence of soil moisture and flooding on formation of VA-endo-and ectomycorrhizae in Populus and Salix. Plant Soil 117:243-253

Lyr H, Hofmann G (1967) Growth rates and growth periodicity of tree roots. International Review of Forestry Research 2:181-236

MacKenzie KA. 1983. Some aspects of the development of the endodermis and cortex of Tilia cordata and Picea sitchensis. In Tree Root Systems and Their Mycorrhizas (pp. 147-153). Springer, Dordrecht

Maeda M (1954) The meaning of mycorrhiza in regard to systematic botany. Kumamoto Journal of Botany 1:57-84

Malajczuk N, Dell B, Bougher NL (1987) Ectomycorrhiza formation in Eucalyptus. III. Superficial ectomycorrhizas initiated by Hysterangium and Cortinarius species. New Phytol 105: 421-428

Malloch D, Malloch B (1981) The mycorrhizal status of boreal plants: species from northeastern Ontario. Can J Bot 59: 2167-2172

Maltz MR, Treseder KK (2015) Sources of inocula influence mycorrhizal colonization of plants in restoration projects: a meta-analysis. Restor Ecol 23:625-634

Mandyam K, Jumpponen A (2005) Seeking the elusive function of the root-colonising dark septate endophytic fungi. Stud Mycol 53:173-189

Manjarrez M, Christophersen HM, Smith SE, Smith FA (2010) Cortical colonisation is not an absolute requirement for phosphorus transfer to plants in arbuscular mycorrhizas formed by Scutellospora calospora in a tomato mutant: evidence from physiology and gene expression. Funct Plant Biol 37:1132-1142

McDougall WB (1914) On the mycorrhizas of forest trees. Am J Bot 1:51-74

McDougall WB (1921) A preliminary key to some forest tree roots. Illinois Acad Sci Trans 14:87-91

Miller DD, Domoto PA, Walker C (1985) Mycorrhizal fungi at eighteen apple rootstock plantings in the United States. New Phytol 100:379-391

Muhsin TM, Zwiazek JJ (2002) Ectomycorrhizas increase apoplastic water transport and root hydraulic conductivity in Ulmus americana seedlings. New Phytol 153:153-158

Müller A, Ngwene B, Peiter E, George E (2017) Quantity and distribution of arbuscular mycorrhizal fungal storage organs within dead roots. Mycorrhiza 27:201-210

Murata H, Yamada A, Yokota S, Maruyama T, Endo N, Yamamoto K, Ohira T, Neda H (2014) Root endophyte symbiosis in vitro between the ectomycorrhizal basidiomycete Tricholoma matsutake and the arbuscular mycorrhizal plant Prunus speciosa. Mycorrhiza 24:315-321

Newman EI, Reddell P (1987) The distribution of mycorrhizas among families of vascular plants. New Phytol 106:745-751

Nunez MA, Horton TR, Simberloff D (2009) Lack of belowground mutualisms hinders Pinaceae invasions. Ecology 90: 2352-2359

Nylund JE (1987) The ectomycorrhizal infection zone and its relation to acid polysaccharides of cortical cell walls. New Phytol 106:505-516

Orchard S, Standish RJ, Dickie IA, Renton M, Walker C, Moot D, Ryan MH (2017) Fine root endophytes under scrutiny: a review of the literature on arbuscule-producing fungi recently suggested to belong to the Mucoromycotina. Mycorrhiza 27: 619-638

Padamsee M, Johansen RB, Stuckey SA, Williams SE, Hooker JE, Burns BR, Bellgard SE (2016) The arbuscular mycorrhizal fungi colonising roots and root nodules of New Zealand kauri Agathis australis. Fungal Biology 120:807-817

Peterson RL, Massicotte HB, Melville LH (2004) Mycorrhizas: anatomy and cell biology. NRC Research Press; Ottawa

Pither J, Pickles BJ, Simard SW, Ordonez A, Williams JW (2018) Below-ground biotic interactions moderated the postglacial range dynamics of trees. New Phytol 220:1148-1160

Polanco MC, Zwiazek JJ, Voicu MC (2008) Responses of ectomycorrhizal American elm (Ulmus americana) seedlings to salinity and soil compaction. Plant Soil 308:189-200

Ray P, Ishiga T, Decker SR, Turner GB, Craven KD (2015) A novel delivery system for the root symbiotic fungus, Sebacina vermifera, and consequent biomass enhancement of low lignin COMT switchgrass lines. BioEnergy Research 8:922-933

Rodriguez RJ, White JF Jr, Arnold AE, Redman AR (2009) Fungal endophytes: diversity and functional roles. New Phytol 182:314-330

Russo RO. 2005. Nitrogen-fixing trees with actinorhiza in forestry and agroforestry. In: Nitrogen fixation in agriculture, forestry, ecology, and the environment (pp. 143-171). Springer, Dordrecht

Selosse M-A, Schneider-Maunoury L, Martos F (2018) Time to re-think fungal ecology? Fungal ecological niches are often prejudged. New Phytol 217:968-972

Sen DN, Jenik J. 1962. Root ecology of Tilia europaea L.: anatomy of Mycorrhizal roots. Nature 193: 1101

Sharda JN, Koide RT (2008) Can hypodermal passage cell distribution limit root penetration by mycorrhizal fungi? New Phytol 180:696-701

Shishkoff N (1987) Distribution of the dimorphic hypodermis of roots in angiosperm families. Ann Bot 60:1-5

Sillo F, Fangel JU, Henrissat B, Faccio A, Bonfante P, Martin F, Willats WG, Balestrini R (2016) Understanding plant cellwall remodelling during the symbiotic interaction between Tuber melanosporum and Corylus avellana using a carbohydrate microarray. Planta 244:347-359

Smith SE, Read DJ (2008) Mycorrhizal symbiosis, 3rd edn. Academic Publisher, Amsterdam

Smith GR, Finlay RD, Stenlid J, Vasaitis R, Menkis A (2017) Growing evidence for facultative biotrophy in saprotrophic fungi: data from microcosm tests with 201 species of wooddecay basidiomycetes. New Phytol 215:747-755

Soudzilovskaia NA, van Bodegom PM, Terrer C, van't Zelfde M, McCallum I, McCormack ML, Fisher JB, Brundrett MC, de Sá NC, Tedersoo L. 2019. Global mycorrhizal plant distribution linked to terrestrial carbon stocks. Nat Commun 10(1):1-0

Soudzilovskaia NA, Vaessen S, Barcelo M, He J, Rahimlou S, Abarenkov K, Brundrett M, Gomes SIF, Merckx V, Tedersoo L (2020) FungalRoot: Global online database of plant mycorrhizal associations. New Phytologist (in press)

Steidinger BS, Crowther TW, Liang J, Van Nuland ME, Werner GD, Reich PB, Nabuurs G, de- Miguel S, Zhou M, Picard N, Herault B (2019) Climatic controls of decomposition drive the global biogeography of forest-tree symbioses. Nature 569(7756):404-408 
Sun T, Zhang H, Wang Z (2019) Reply to Tedersoo et al.: plant species within the same family or genus can have different mycorrhizal types? Proc Natl Acad Sci 116:12141-12142

Tedersoo L, Brundrett MC. 2017. Evolution of ectomycorrhizal symbiosis in plants. In: Biogeography of Mycorrhizal Symbiosis. Springer, Cham, 407-467

Tedersoo L, Smith ME. 2017. Ectomycorrhizal fungal lineages: detection of four new groups and notes on consistent recognition of ectomycorrhizal taxa in high-throughput sequencing studies. In: Biogeography of Mycorrhizal Symbiosis (pp. 125-142). Springer, Cham

Tedersoo L, Rahimlou S, Brundrett M (2019) Misallocation of mycorrhizal traits leads to misleading results. Proc Natl Acad Sci 116:12139-12140

Tedersoo L, Bahram M, Zobel M (2020) How mycorrhizal associations drive plant population and community biology. Science 367:eaba1223

Thakur JS, Sharma YP (2013) Effect of ectomycorrhizal inoculation on the growth of apple seedlings. Plant Disease Research (Ludhiana) 28:35-38

Thoen E, Harder CB, Kauserud H, Botnen SS, Vik U, Taylor AFS, Menkis A, Skrede I (2020) In vitro evidence of root colonization suggests ecological versatility in the genus Mycena. New Phytol 227:601-612. https://doi.org/10.1111 /nph.16545

Tian C, He X, Zhong Y, Chen J (2003) Effect of inoculation with ecto-and arbuscular mycorrhizae and Rhizobium on the growth and nitrogen fixation by black locust, Robinia pseudoacacia. New For 25:125-131

Tisserant B, Schellenbaum L, Gianinazzi-Pearson V, Gianinazzi S, Berta G (1990) Influence of infection by an endomycorrhizal fungus on root development and architecture in Platanus acerifolia. Allionia 30:171-181

Toju H, Sato H, Tanabe AS (2014) Diversity and spatial structure of belowground plant-fungal symbiosis in a mixed subtropical forest of ectomycorrhizal and arbuscular mycorrhizal plants. PLoS One 9(1):e86566

Trappe JM (1987) Phylogenetic and ecologic aspects of mycotrophy in the angiosperms from an evolutionary standpoint. In: Safir GR (ed) Ecophysiology of VA mycorrhizal plants. CRC Press, Boca Raton, Florida, pp 5-25

Trappe JM (2005) AB Frank and mycorrhizae: the challenge to evolutionary and ecologic theory. Mycorrhiza 15:277-281

Valverde-Barrantes OJ, Freschet GT, Roumet C, Blackwood CB (2017) A worldview of root traits: the influence of ancestry, growth form, climate and mycorrhizal association on the functional trait variation of fine-root tissues in seed plants. New Phytol 215:1562-1573

Varma A, Verma S, Sahay N, Bütehorn B, Franken P (1999) Piriformospora indica, a cultivable plant-growth-promoting root endophyte. Applied Environmental Microbiology 65: 2741-2744

Wagg C, Pautler M, Massicotte HB, Peterson RL (2008) The cooccurrence of ectomycorrhizal, arbuscular mycorrhizal, and dark septate fungi in seedlings of four members of the Pinaceae. Mycorrhiza 18:103-110

Walker C (1995) AM or VAM: What's in a word? In: Mycorrhiza. Springer-Verlag, Berlin, pp 25-26

Waller LP, Callaway RM, Klironomos JN, Ortega YK, Maron JL (2016) Reduced mycorrhizal responsiveness leads to increased competitive tolerance in an invasive exotic plant. J Ecol 104:1599-1607

Weerdenburg CA, Peterson CA (1983) Structural changes in phi thickenings during primary and secondary growth in roots. 1 . Apple (Pyrus malus) Rosaceae. Can J Bot 61:2570-2576

Wilson GW, Hartnett DC (1998) Interspecific variation in plant responses to mycorrhizal colonization in tallgrass prairie. Am J Bot 85:1732-1738

Xi Z, Ruhfel BR, Schaefer H, Amorim AM, Sugumaran M, Wurdack KJ, Endress PK, Matthews ML, Stevens PF, Mathews S, Davis CC (2012) Phylogenomics and a posteriori data partitioning resolve the cretaceous angiosperm radiation Malpighiales. Proc Natl Acad Sci 109:17519-17524

Publisher's note Springer Nature remains neutral with regard to jurisdictional claims in published maps and institutional affiliations. 